\title{
BIBLIOGRAFIE VAN DE GESCHIEDENIS VAN GENT 1994-1995
}

\author{
Leen Charles, René De Herdt en Marie Christine Laleman
}

\begin{abstract}
Stadsarchief Gent, Museum voor Industriële Archeologie en Textiel en Dienst Stadsarcheologie
\end{abstract}

\begin{abstract}
Inhoud ${ }^{1}$
Inventarissen, archiefbeschrijvingen, repertoria, bibliografieën (nr. 251-281), Archeologische kronieken (nr. 282-291), Algemeen (nr. 292-298), Prehistorie, Romeinse en Merovingische tijden (nr. 299-302), Middeleeuwen (nr. 303-312), Moderne Tijden (nr. 313-327), Hedendaagse tijd (nr. 328-346), Industriële archeologie (nr. 347-353), Kerkgeschiedenis, kloosters (nr. 354-364), Gebouwen, monumenten, stadsbeeld (nr. 365-410), Kunst, cultuur (nr. 411-437), Materiële cultuur (nr. 438-442), Heemkunde, volkskunde, genealogie (nr. 443490), Biografieën (nr. 491-520).
\end{abstract}

Inventarissen, archiefvoorstellingen, repertoria en bibliografieën

251. AERTS E., M. BAELDE, H. COPPENS, H. DE SCHEPPER, H. SOLY, A. K. L. THIJS en K. VAN HONACKER (ed.), De centrale overheidsinstellingen van de Habsburgse Nederlanden (1482-1795), (Algemeen Rijksarchief en Rijksarchief in de Provinciën, Studia nr. 55), Brussel, 1994, 2 dln., 981 blz.

Repertorium met per instelling: geschiedenis, organisatie, bevoegdheden en activiteiten, bibliografie, archiefbewaarplaatsten en -toegangen, bronnenpublikaties. Met aandacht voor het huidige Frankrijk, Nederland, Spanje en Oostenrijk. Enkele instellingen lieten te Gent archiefmateriaal na: de Staten-Generaal (Stadsarchief, Universiteitsbibliotheek), de Jointe voor Amortisaties, de Admiraliteiten, de Keizerlijke en Koninklijke Loterij, de Jointe voor de runderpest te Gent en de Koninklijke Bibliotheek (Rijksarchief) en het Seminarie-Generaal en SeminarieFiliaal (Bisschoppelijk Seminarie). Met register van de instellingen.

252. BOURGOIS M., Fonds Stefaan Mortier (1857-1934) in het patrimonium Sint-Lucas Gent, in Jaarboek Hoger Architectuurinstituut Sint-Lucas 1993-1994, (Centrum voor Architectuuronderzoek), z.pl., p. 23-35.

Stefaan Mortier speelde onder meer als Provinciaal Architect van Oost-

1 De boeken en artikels in deze bibliografie opgenomen, worden met ingang van 1994 doorlopend genummerd. Dit zal na verloop van tijd de opmaak van algemene indices vergemakkelijken. 


\section{CHARLES, R. DE HERDT, M.C. LALEMAN}

Vlaanderen (1889-1923) een belangrijke rol in het behoud van het Gentse gebouwenpatrimonium. Geillustreerd.

253. CHARLES L., Inventaris reeks U Onderwijs (19de-begin 20ste eeuw), (Stad Gent. Inventarissen en indices gepubliceerd doorhet Stadsarchief), Gent, 1994 , 115 blz.

Inventaris van de stukken betreffende het onderwijs te Gent in de 19de eeuw. Met indices op instellingen, persoons-, plaats- en straatnamen.

254. CHARLES L., Voorlopige inventaris van de reeks G Openbare Werken (19de-begin 20ste eeuw), (Stad Gent. Inventarissen en indices gepubliceerd door het Stadsarchief), Gent, 1994,225 blz.

Inventaris van een deel van de archiefbescheiden over Openbare Werken te Gent in de $19 \mathrm{de}$ en het begin van de 20ste eeuw. Met indices op namen van gebouwen, instellingen, perceelsnummers, persoons- en straatnamen.

255. CHARLES L., Reeks G Openbare Werken. Regestenlijst van notarisakten (secties 1 en 2), (Stad Gent. Inventarissen en indices gepubliceerd door het Stadsarchief), Gent, 1994 , 42 blz. en 29 blz.

Regesten van de notariële akten aanwezig in de dossiers van Openbare Werken. Met indices op notarissen, persoons- en straatnamen.

256. CHARLES L. en D. LIEVOIS, Inventaris reeks DD Stukken betreffende het Kadaster, (Stad Gent. Inventarissen en indices gepubliceerd door het Stadsarchief), Gent, 1995, 5 blz.

Inventaris van de kadastrale bescheiden bewaard in het Stadsarchief. Met indices op straatnamen.

257. DECOCKER J., Staten van goed van Melsen 16.12.1752-9.2.1796, z. pl., 1994, 17 blz.

258. DEHERDTR., M.C.LALEMANen J.VANNIEUWENHUYSE, Bibliografie van de geschiedenis van Gent 1993-1994, in Handelingen der Maatschappij voor Geschiedenis en Oudheidkunde, XLVIII, (1994), p. 233-278.

259. DE KOOKER H.W. en B. VAN SELM, Boekcultuur in de Lage Landen 1500-1800. Bibliografie van publikaties over particulier boekenbezit in Noord- en Zuid-Nederland, verschenen voor 1991, Utrecht, 1993, XVII en 210 blz.

Bij de boekeigenaren worden vermeld: naam, geboorte- en sterfjaar, opleiding, formele beschrijving van het boek, aard van de bron over het boek, taal waarin het is gesteld. Voor Gent komen aan bod: de bibliotheken van de graaf van Egmont in het Gravensteen (1568), van boekbezitter Willem van den Bogaerde (ca. 1571), van Haymann Adam (ca. 1570), 
van Filips van Kleef, heer van Ravenstein (ca. 1528), van Elisabeth de Grutere, weduwe van Simon Borluut (ca. 1500) en van Raphaël de Mercatellis (1572). Met een chronologisch register (vanaf 1488), een register van de auteurs van de publikaties, plaats- en streeknamen en een register van beroepen en functies van de boekenbezitters.

260. DE LILLE G., Parochieregisters 1616-1796 Oostwinkel. Dopen, Huwelijken en Overlijdens, (Heemkundige Kring Het Ambacht Maldegem), Maldegem, 1994, 2 dln., 450 blz., 216 blz. en 218 blz.

261. DEVOLDER K., Gij die door ' $t$ volk gekozen zijt ... De Gentse gemeenteraad en haar leden 1830-1914, (Verhandelingen der Handelingen der Maatschappij voor Geschiedenis en Oudheidkunde, XX), Gent, 1994, 555 blz..

Politiek-biografisch repertorium van de gemeenteraadsleden, met een studie van de werking van de gemeentelijke instellingen in de 19de eeuw, de evolutie van de kieswetgeving en de electorale geschiedenis van Gent tussen 1830-1914. Met repertorium van de verkiezingsuitslagen.

262. D'HONDT B., Inventaris van het Archief van Henry Story (1897-1944), (Liberaal Archief, Reeks Inventarissen, nr. 4), Gent, 1994, 45 blz.

Inventaris van het archief met bio-politieke beschrijving van de liberale textielindustrieel, lid van de raad van beheer van La Flandre Libérale en verzetsstrijder. Hij overleed in het kamp van Grosz Rosen. Met personenregister.

263. FLOUR E. en C. JACQUES, Bronnen voor de geschiedenis van de vrouwenbeweging in België. Repertorium van archieven 1830-1993, Brussel, 1993, VII en 339 blz.

Voor Gent worden behandeld: het Archief en Museum van de Socialistische Arbeidersbeweging (AMSAB), het Liberaal Archief en de Universiteit (Genderfonds en het Universiteitsarchief), de Federatie van Vlaamse Vrouwengroepen, Tegen Haar Wil en de Vrouwenbond voor Katholieke Actie; tenslotte de privé-papieren van Marijke Colle en Henriette d'Hollander-De Backer. Met indices op organisaties, personen, archiefen documentatiecentra.

264. Het archief van Tuur De Decker, in AMSAB-Tijdingen, n.r., (1995), nr. 26, p. 15.

Bevat stukken van de werking van het "Gents Dopperskomitee" (periode 1975-1978) waarvan De Decker (Ninove, 1952) een woordvoerder was; ook stukken betreffende het Ninoofs Progressief Front, zijn tweede grote actieterrein. 


\section{CHARLES, R. DE HERDT, M.C. LALEMAN}

265. JANSSENS G., "Verjaagd uit Nederland": Zuidnederlandse emigratie in de zestiende eeuw, een historiografisch overzicht (ca. 1968-1994), in Nederlands archief voorkerkgeschiedenis, 75, (1995), nr. 1, p. 102-119.

266. LIEVIJNS L., Repertorium van de pers en perioden bewaard op het AMSAB, 1831-1940, (Archief en Museum van de Socialistische Arbeidersbeweging AMSAB, Werkinstrumenten, 3), Gent, 1995, 339 blz. Handig werkinstrument ( 831 titels) over de linkse syndicale en coöperatieve pers in België.

267. MERTENS J., Het O.C.M.W.-archief in het gerechtelijk arrondissement Gent. Inspectierapport, (Algemeen Rijksarchief en Rijksarchief in de Provinciën. Miscellanea Archivistica Studia, nr. 38), Brussel, 1993, 26 blz.

268. POELMAN R., Alfabetische index op de telling van 1796 in Oostakker, in De Oost-Oudburg. Jaarboek, XXXI, (1994), p. 19-91.

269. ORIS M., M. PAULY en M. RYCKAERT (red.), Bibliographie de l'histoire urbaine. Belgique - Luxembourg. Bibliografie van de Stadsgeschiedenis. België - Luxemburg. Bibliographie zur Stadtgeschichte. Belgien - Luxemburg, 1992-1993, Liège, 1994, 164 blz.

Bibliografisch overzicht van publikaties met betrekking tot stadsgeschiedenis over de jaren 1992-1993 en met verscheidene verwijzingen naar Gent.

270. SCHREURSE.en B.BOUCKAERT(red.), Bedreigde klanken? Muziekfragmenten uit de Lage Landen (Middeleeuwen - Renaissance), (Alamire Foundation \& Muziekuitgeverij), Leuven-Peer, 1995, 69 blz.

Overzicht voor de Lage Landen van weinig bekende en vaak fragmentarisch bewaarde handschriften met muzieknotities uit de $15 \mathrm{de}-16 \mathrm{de}$ eeuw. Gent komt er onder meer aan bod met een blad uit een polyfone codex, afkomstig uit de abdij van de Groenebriel (kort vóór 1400) en met een leisteenfragment dat op het Sint-Baafsplein werd opgegraven en mogelijk een muzieknotitie uit de 15 de eeuw toont.

271. STEEGHERS W., Dodenlijst van het klein begijnhof Onze-Lieve-Vrouw ter Hooie te Gent (1610-1685), in Vlaamse Stam, 31, (1995), nr. 5, p. 261269.

272. VAN BELLE J.L., Nouveau Dictionnaire des signes lapidaires. Belgique et Nord de la France, Namur, 1995.

Uitgebreide inventaris van steenhouwersmerken die de jongste twintig jaar op gebouwonderdelen, voornamelijk van hardsteen, werden geregistreerd en in het Centre International de Recherches Glyptographiques 
werd bijgehouden. Behalve inleidende gedeelten over de betekenis van dergelijke merktekens, de inventaris per gemeente en gebouw, en de morfologische klassering van de bekende merktekens voor België en Noord-Frankrijk, worden in zoverre mogelijk, ook inlichtingen gegeven over de datering, de steenhouwer(s) die het merkteken zetten en het milieu waarin zij werkzaam waren. Hoewel het overzicht voor Gent niet gebaseerd is op systematische prospectie en registratie, worden er toch heel wat gegevens over deze stad opgenomen. Ze geven bijgevolg informatie over steenhouwers die in deze stad werkten of afgewerkte produkten leverden voor bouwactiviteiten. De betreffende inventaris maakt het verder mogelijk de lokale data in een ruimer perspectief te evalueren.

273. VAN BUTSELE P., Alfabetische klappers met genealogische analyses op de staten van goederen van Oudenaarde, $a^{\circ}$ 1584-1589. Register $n r$. 33, (Stadsarchief), Oudenaarde, 1995, 174 blz. Zie ook ID., Alfabetische klappers met genealogische analyses op de staten van goederen van Oudenaarde, $a^{\circ}$ 1589-1594. Registernr. 34, (Stadsarchief), Oudenaarde, 1995, 162 blz. en ID., Alfabetische klappers met genealogische analyses op de staten van goederen van Oudenaarde, $a^{\circ} 1595-1600$. Register $n r$. 35, (Stadsarchief), Oudenaarde, 1995, 134 blz.

274. VAN DER KROGT P., M. HAMELEERS en P. VAN DEN BRINK, Bibliografie van de Geschiedenis van de Kartografie van de Nederlanden. Bibliography of the History of Cartography of the Netherlands, Utrecht, 1993, 418 blz.

Bevat publikaties (4564 nummers) over de geschiedenis van de kartografie. Geografisch bestrijkt het werk het grondgebied van de voormalige Zeventien Provinciën, met name het huidige Nederland, België en Luxemburg. Beperkt tot publikaties verschenen na het midden van de 19de eeuw. Met regionale index en indices op auteurs en persoonsnamen.

275. VANDER MAELEN H. en D. VERKERKEN, Necrologium SintStefanusklooster Gent 2, Gent, 1994, 66 blz.

276. VANHEE T., Deinze-Nazareth-Eke, Zulte. Een documentatiegids voor historisch en genealogisch onderzoek in het Rijksarchief van Kortrijk, (Vlaamse Vereniging voor Familiekunde-Afdeling Deinze), Deinze, 1994, 131 blz.

Bronnen in het Kortrijkse Rijksarchief: publiekrechterlijke en kerkelijke instellingen, familiearchieven. Met index op persoonsnamen en een trefwoordenindex per gemeente.

277. VAN ISTERDAEL H., Archief van het Land van Aalst 1342-1796 (1814) delen I-V, (Rijksarchief te Beveren. Inventarissen, nr. 11), Brus- 


\section{CHARLES, R. DE HERDT, M.C. LALEMAN}

sel, 1994, $1200 \mathrm{blz}$.

Met uitgebreide inleiding ( $168 \mathrm{blz}$.) en uitvoerige indices op persoons- en plaatsnamen.

278. VERKERKEN D., Overledenen tussen einde 1814 en begin 1818 in en rond het Patershol te Gent. Uit het register van de parochie SintStefanus, in VVF-InformatiebladAfdeling Gent, XIV, (1995), nr. 2, p. 2930 ; nr. 3, p. 43-44.

279. VERKERKEN D., Professieboek der fraters en broeders Augustijnen van Gent 1622-1689, Gent, z. blz.

Alfabetische naamlijst van de Augustijnen die in het Gentse klooster de gelofte aflegden.

280. VEROUGSTRAETE J., Inventaris van de Belgische bibliotheken en Documentatiecentra, (Koninklijke Bibliotheek, Nationaal Centrum voor Wetenschappelijke en Technische Documentatie), Brussel, 1994,693 blz. Met handig register op instellingen en onderwerpen.

281. VIAENE P., Bibliografie Industriële Archeologie en Industrieel Erfgoed in België IV, in Tijdschrift voor Industriële Cultuur, 12, (1994), nr. 3, p. 3-23. Geillustreerd.

Archeologische kronieken

282. BUYLE M. en A. BERGMANS, Middeleeuwse muurschilderingen in Vlaanderen, (Monumenten en Landschappen, Cahier 2), Brussel, 1994, 208 blz.

Voor Gent worden behandeld: de refter van de voormalige abdij van de Bijloke, het Geraard de Duivelsteen, het Huis Spijkeboort (Geldmunt 22), het Groot Vleeshuis, het voormalig pand van de Dominicanen te Onderbergen, de voormalige Sint-Baafsabdij, de crypte van de SintBaafskathedraal en de Sint-Niklaaskerk. Met verklarende woordenlijst en bibliografie. Geîllustreerd. Zie ook: BUYLE M., Middeleeuwse muurschilderingen, in Openbaar Kunstbezit in Vlaanderen, 33, (1995), nr. 1, p. 3-39. Geillustreerd.

283. DE MEULEMEESTER J., M.C. LALEMAN en A. MATTHYS (ed.), Archaeologia Mediaevalis, 18, (1995), 100 blz., met bijhorend bibliografisch overzicht 20 blz.

Samenvattingen van de middeleeuwse en post-middeleeuwse archeologie in de zuidelijke Nederlanden en de aangrenzende gebieden op basis van terreinwerk en onderzoeksprojecten in 1994. 
284. DEMIDDELE H. en A. ERVYNCK, Diatomeeën: ecologische indicatoren in de archeologie, in Archaeologia Mediaevalis, 18, (1995), p. 7-8.

Korte notitie over de studie van diatomeeën of kiezelwieren uit archeologische contexten voor de reconstructie van het milieu, met verwijzing naar onderzoeksresultaten aan de Gouvernementstraat en de Hogeweg in Gent.

285. HOFFSUMMER P. en D. HOUBRECHTS, Dendrochronologie en Belgique et régions limotrophes, in Archaeologia Mediaevalis, 18, (1995), 2, p. 3-4.

In dit beknopte overzicht van dendrochronologisch onderzoek door het Laboratoire de Dendrochronologie verbonden aan de Université de Liège over 1994 worden de resultaten voor de dakconstructies boven de kerk van de Geschoeide Karmelieten aan de Lange Steenstraat kort toegelicht.

286. LALEMAN M.C., L'archéologie de la ville en Belgique : quelques réflexions, in Actes du LIe Congrès de la Fédération des Cercles d'Archéologie et d'Histoire de Belgique, Liège, 1994, nr. 2, p. 122-128. Beknopt overzicht van het archeologisch stadsonderzoek in België, met vermelding van Gent.

287. LALEMAN M.C., Het Sint-Baafsdorp, een archeologisch-historische kennismaking, in Heemkundig nieuws, XXII, 1994, nr. 4, p. 2-3.

Samenvatting over de bijdrage van de archeologie voor de kennis over het Sint-Baafsdorp.

288. LALEMAN M.C., A. LENS, D. LIEVOIS en G. STOOPS, Stadsarcheologisch onderzoek in Gent (O.Vl.), in Archaeologia Medievalis, 18, (1995), p. 46-49.

Overzicht van de archeologische interventies in 1994 en van de belangrijkste onderzoeksresultaten.

289. Vondstmeldingen, in Stadsarcheologie. Bodem en Monument in Gent, 18, (1994), nr. 1, p. 31-40.

Mededelingen van archeologische bevindingen en vondsten: bouwontwikkeling en wandschilderingen in de refter van de Sint-Pietersabdij en in de kamers op de onderliggende verdieping (Sint-Pietersplein), opbouw van het bodemarchief (Sint-Veerleplein), gegevens over middeleeuwse stenen huizen (Veldstraat), bouwkundige ontwikkelingen en vondst van een 17de-eeuwse bouwsculptuur in het klooster van de geschoeide karmelieten (Vrouwebroersstraat). Geïllustreerd.

290. Vondstmeldingen, in Stadsarcheologie. Bodem en Monument in Gent, 18, (1994), nr. 2, p. 51-65. 


\section{CHARLES, R. DE HERDT, M.C. LALEMAN}

Mededelingen van archeologische bevindingen en vondsten: de bouwhistorische ontwikkeling van de kapel bij de ziekenzaal van de Bijloke, laat-middeleeuwse bouwpotten, 13de-eeuwse wandschilderingen in die kapel met jongere overschilderingen en een vermoedelijk 18de-eeuwse Christusschildering met jongere hernemingen aan de oostwand van de ziekenzaal (Bijlokekaai), post-middeleeuwse huisraad in het Krijgsgasthuis (Ekkergemstraat), restanten van de abdijkerk en de bouwkundige ontwikkeling van de refter van de Sint-Baafsabdij (Gandastraat), resten van een middeleeuwse houtbouw en de opbouw van het terrein in een deel van het Patershol (Kraanlei-Hertogstraat), de opbouw van de Rabotfortificatie en de aarden stadsvest die er ten noorden bij aansloot (Rabot), enkele bouwkundige gegevens over de huizenrij aan de rooilijn en de vermoedelijke resten van laat-middeleeuwse tegeloven (SintAntoniuskaai 11-22), restanten van een mestvaalt met huisraad, beenderen, zaden, vruchten en insektenresten, evenals een houten tonput uit de late middeleeuwen (Sint-Michielsplein-Wilderoosstraat), de bouwkundige ontwikkeling van de reftervleugel van de Sint-Pietersabdij en de vondst van een massa geprofileerde stukken, vooral vensteronderdelen in witte natuursteen, die in een 18de-eeuwse gewelfstructuur waren verwerkt (Sint-Pietersplein). Geilllustreerd.

291. Vondstmeldingen, in Stadsarcheologie. Bodem en monument in Gent, 19, (1995), nr. 1, p. 40-56.

Mededelingen van archeologische bevindingen en vondsten: bouwkundige sporen en reconstructie van ontwikkelingsfazen voor de middeleeuwse ziekenzaal en de bijhorende kapel van de Bijloke, vondsten van bouwpotten en vensterglas, dendrochronologische gegevens voor de kapel (Bijlokekaai), de restanten van een middeleeuws stenen stadshuis met jongere verbouwingen (Drabstraat), een muurrest in Doornikse steen (Kortrijksepoortstraat), middeleeuwse en jongere sporen, vermoedelijk van het verdwenen Franciscanerklooster (Kuipgat), muurresten van een middeleeuws stadshuis (Langemunt/Onderstraat), gebouwsporen en diverse ontwikkelingsfazen van de voormalige kerk der geschoeide karmelieten, evenals bijzettingen onder meer in grafkelders met beschilderde wanden (Lange Steenstraat), gegevens over de ontwikkeling van het Klein Begijnhof en de stadsfortificatie nabij de Vijfwindgatenpoort (Lange Violettenstraat), de resten van een 16de-eeuws penshuisje (Pensmarkt), middeleeuwse lagen (Sint-Veerleplein), hardstenen vorstpannen met steenhouwersmerken uit de 17de eeuw en gegevens over de oude kruisgang van het voormalige klooster van de geschoeide karmelieten (Vrouwebroersstraat). Geíllustreerd. 
Algemeen

292. ART J. (red.), Hoe schrijf ik de geschiedenis van mijn gemeente? deel 2 . 12de-18de eeuw, (Centrum voor Geschiedenis Universiteit Gent), Gent, 1994, 263 blz.

Met bijdragen van R. VERMEIR, De voornaamste bibliografische instrumenten, bronnenpublikaties en archieven (p. 13-37), M. BOONE, Politiek-institutionele en sociaal-economische geschiedenis (12de-begin 16de eeuw) (p. 39-84), K. DEGRYSE, Politiek-institutionele en sociaal-economische geschiedenis(16de-18deeeuw): een bronnenstudie (p. 85-101), C. VANDENBROEKE, Sociaal-economische geschiedenis (16de-18de eeuw) (p. 103-135) en ID., Historische demografie (p. 137186), M. VLEESCHOUWERS, Kerkgeschiedenis (12de-16de eeuw) (p. 187-229) en M.J. MARINUS, Kerkgeschiedenis (16de-18de eeuw) (p. 231-259).

293. BAILLIEUL B., De Gentse schuttersgilden nog steeds in het verweer, in Oostvlaamse Zanten, LXX, (1995), nr. 1, p. 49-71.

Historiek van de voetboogschutters van Sint-Joris (voor 1314), de handboogschutters van Sint-Sebastiaan (1322), de kolveniers van SintAntonius (1488) en de schermers van Sint-Michiels (1613); later kwamen hier nog bij de kruisboogmaatschappij van Sint-Rochus (1820), de kleine kruisboogvereniging Willem Tell (1825) en tenslotte de balboogvereniging Nemrod (1843). Zie ook ID., De Sint-Rochusgilde is 175 jaar jong, in Toerisme Oost-Vlaanderen, 44, (1995), nr. 3, p. 38-42.

294. DE BUCK R., Van Wijn in Gent tot Gent in wording. De Gentse wijnhandel tussen 1302 en 1795 en de wordingsgeschiedenis van Gent, Gent, 1995, 430 blz.

Behandelt de wijnhandel te Gent tussen 1302 en 1795. Besteedt aandacht aan de diverse ambachten betrokken bij de wijnhandel en het wijntransport. Het gebruik van de presentwijn komt aan bod. In een tweede gedeelte behandelt de auteur het "Leiewad" dat zich onder het Wijnschrodershuis aan de Kraanlei bevond. Hij stelt nieuwe hypothesen voor over de wordingsgeschiedenis van Gent, onder meer over het tracé van de handelsassen doorheen Gent en de lokalisatie van de eerste twee bruggen en de vier oudste stadspoorten. Geillustreerd. Zie ook ID., Wijnhandel in historisch Gent, in G.O.V. Heraut, 30, (1995), nr. 3, p. 1520.

295. DECAVELE J., Die historische Rolle der Stadt Gent in der Entwicklung Flanderns und der Gesamt-Niederlande, in Niederländische Studien, (Universität Duisburg Gesamthochschule), (1995), p. 1-12. 


\section{CHARLES, R. DE HERDT, M.C. LALEMAN}

296. PILLE F. (red.), Geschiedenis van Evergem, Aalter, 1994, 2dln., LX en 845 blz.

Synthese van de geschiedenis van Evergem vanaf de prehistorie, met ruime aandacht voor de instellingen en de politieke, religieuze en sociaaleconomische ontwikkelingen; het verenigingsleven komt eveneens ruim aan bod. Geillustreerd.

297. SCHENKEVELD-VAN DER DUSSEN M.A., Nederlandse Literatuur, een geschiedenis, Groningen, 1993, XXX en 938 blz.

Met bijdragen betreffende Gent: D. COIGNEAU, 9 december 1448: Het Gentse stadsbestuur keurt de statuten van de rederijkerskamer "De Fonteine" goed - Literaire bedrijvigheid in stads-en gildeverband (p. 102-108); W. HUMMELEN, 12-23 juni 1539: Negentien rederijkerskamers nemen deel aan een wedstrijd te Gent - Rederijkersdrama en reformatie (p. 142- 146); H. PLEIJ, 7 maart 1500: De Brusselse stadsrederijker Jan Smeken is uitgezonden naar Gent om te berichten over de doopfeesten van Karel $V$ - De rederijkerij als beschavingsinstituut (p. 121-126); ID., 24 februari 1527: Intree te Gent op vastenavond van de zottenkeizer - Het repertoire van de volksfeesten (p. 137-142); J. SMEYERS, 2 januari 1779: In Gent verschijnt het eerste Nederlandstalige weekblad-Spectatoriale geschriften in de Zuidelijke Nederlanden, (p. 351-354); W. WATERSCHOOT, 1 juli 1565: Lucas d'Heere draagt "Den Hof en boomgaerd der poësien" op aan de hoogbaljuw van Gent - De vroege renaissance in Vlaanderen (p. 152-158); A.M. MUSSCHOOT, Najaar 1903: Van de Woestijnes bundel "Het vader-huis" wordt gedrukt op de handpers van J. De Praetere - Karel van de Woestijne en het symbolisme (p. 581-586).

298. VANDER KROGT P., Erdgloben, Wandkarten, Atlanten - Gerhard Mercator kartiert die Erde, in Gehrard Mercator. Europa und die Welt, (Stadt Duisburg, Kultur- und Stadthistorische Museum Duisburg), Duisburg, 1994, p. 81-129.

Herneemt onder meer de theorie van R. Kirmse, die zegt dat Mercator zijn beroemde kaart van Vlaanderen in 1540 zou vervaardigd hebben in opdracht van kooplui die Keizer Karel na de opstand van Gent in 15391540 gunstig wilden stemmen door hem een nieuwe kaart van Vlaanderen aan te bieden. Geîllustreerd.

Prehistorie, Romeinse en Merovingische tijden

299. CROMBE P. en G. VAN DER HAEGEN, Gents alleroudste relicten. Vuursteenwerktuigen uit het Midden-Paleolithicum, in Stadsarcheologie. Bodem en monument in Gent, 18, (1994), nr. 1, p. 5-10.

Samenvatting van alle gegevens met betrekking tot de oudste archeologische voorwerpen die in het Gentse aan het licht kwamen. Geillustreerd. 
300. DE COSTER P., Een Romeinse munt gevonden te Kalken, in Castellum, XII, (1995), nr. 3, 3-8.

Betreft de vondst van een dupondius op de akker "het Rot", daterend uit de tijd van keizer Trajanus (114-117). Geilllustreerd.

301. VERMEULEN F., Ontdekking van een prehistorisch nederzettingsterrein in Sint-Martens-Latem, in Heemkring Scheldeveld. Jaarboek, XXIII, (1994), p. 3-6.

302. VERMEULEN F., M. ROGGE en L. VAN DAMME (red.), Terug naar de bron. Kruishoutem archeologisch doorgelicht, (Archeologische Inventaris Vlaanderen, Buitengewone Reeks, nr. 2), Gent, 1993, 224 blz. Archeologisch overzicht van Kruishoutem vanaf de oudste sporen van voor- en vroeghistorische bewoning en met specifieke aandacht voor het onderzoeksproject op de Kapellekouter (onder meer een Gallo-Romeinse vicus en een middeleeuws grafveld). Met verwijzing naar "kaarten en plannen" over het gebied en een uitgebreide bibliografie. Geillustreerd.

\section{Middeleeuwen}

303. BOONE M., Bourgondië en Vlaanderen. Van dynastieke eenheid naar natievorming, in Vlaanderen, 44, (1995), nr. 2, p. 75-80.

Beknopt historisch overzicht van de Bourgondische periode met klemtoon op de politieke betekenis van Vlaanderen en met verwijzingen naar specifieke gebeurtenissen, zoals onder meer het huwelijk van Filips de Stoute en Margaretha van Male in Gent in 1369, de Gentse opstand van 1379-1385, de slag bij Gavere in 1453, de opvolgingsperikelen na het overlijden van elke hertog en zeker bij de plotse dood van Karel de Stoute in 1487. Geîllustreerd.

304. DECAVELE J., C. VAN BRUWAENE en L. LEKENS, Jacob van Artevelde, Het zevenjarig bewind van de Wijze Man van Gent 1338-1345, met wandelgids, (Stad Gent), Gent, 1995, 64 blz.

Brochure naar aanleiding van de 650ste verjaardag van de moord ( 17 juli 1345) op Jacob van Artevelde. Biografische nota en historische situering. Geillustreerd.Zie ook: DE BUCKR., Jacob VanArtevelde, in Ghendtsche Tydinghen, 24, (1995), nr. 3, p. 134-152 en KLUYSKENS P., De moord op Jacob Van Artevelde, in Ghendtsche Tydinghen, 24, (1995), nr. 4, p. 207-210.

305. DEVAUX J., Les soulèvements urbains de 1477 sous le regard des chroniqueurs du temps, in Actes du LIe Congrès de la Fédération des Cercles d'Archéologie et d'Histoire de la Belgique, Liège, 1994, nr. 2, p. 391-411. 


\section{CHARLES, R. DE HERDT, M.C. LALEMAN}

De auteur gaat dieper in op de getuigenverslagen in kronieken over de politieke en institutionele crisis van 1477 en neemt als uitgangspunt de bijeenkomst van de Staten-Generaal in Gent op 11 februari 1477.

306. GORIS M. en W. WISSINK, A priori: een leeseditie van de Gentse Boethius, in Madoc. Tijdschrift over de Middeleeuwen, 9, (1995), nr. 1, p. 43-45.

Naar aanleiding van de op stapel staande editie van de anonieme "Gentse Boethius", uitgegeven bij Arend de Keysere in Gent (1485) en bewaard in Den Haag (K.B., 171 A2). Eén van de twee bekende becommentarieerde Middelnederlandse versies van het filosofisch tractaat De Consolatione philosophiae uit de 6de eeuw.

307. MURRAY A.V., Voices of Flanders: Orality and constructed Orality in the Chronicle of Galbert of Bruges, in Handelingen der Maatschappij voor Geschiedenis en Oudheidkunde te Gent, XLVIII, (1994), p. 103-119.

De kennis over de moord op graaf Karel de Goede, in de Sint-Donaaskerk te Brugge op 2 maart 1127, evenals de politieke en sociale gebeurtenissen die erop volgden en geheel Vlaanderen in een conflictsituatie meesleurden, zijn het best bekend door het unieke getuigenverhaal van Galbert van Brugge. Deze bron werd reeds herhaaldelijk bestudeerd en van commentaar voorzien. Voor het eerst wordt evenwel ruime aandacht geschonken aan de mondelinge bronnen waarop de kroniek zich baseerde en hoe Galbert die redevoeringen of gesproken teksten in het hele verhaal verwerkte. Die bronnen zijn niet uit hun politieke context weg te denken, maar bieden bovendien heel wat inlichtingen voor de mentaliteitsgeschiedenis. De auteur illustreert deze beknopte samenvatting van zijn studie aan de hand van een aantal concrete voorbeelden, waaronder de rede die Iwein van Aalst, heer van Drongen, als woordvoerder namens Gent in februari 1128 uitsprak.

308. NICHOLAS D., In the Pit of the Burgundian Theater State: Urban Traditions and Princely Ambitions in Ghent, 1360-1420, in HANAWALT B. en K. REYERSON (ed.), City and Spectacle in Medieval Europe, (Medieval Studies at Minnesota, nr. 6), Minneapolis, 1994, p. 271-295. Hoewel in de periode 1360 tot 1420 een substantiële verhoging van de stedelijke uitgaven voor feestelijkheden (zoals tornooien, schietspelen, processies ...) te Gent te bemerken valt, lijkt men dit niet te kunnen toeschrijven, zoals in andere steden, aan een bewuste zet om de macht van de heersende Bourgondische klasse te verstevigen. Het leeuwendeel van de uitgaven voor festiviteiten is gegaan naar geschenken aan de schepenen. Het heeft er alle schijn van dat de drie leden van het Gentse stadsbestuur stevig genoeg in het zadel zaten en geen behoefte hadden aan dat soort festiviteiten om de sociale controle te behouden. De jaarlijkse deelname aan de Onze-Lieve-Vrouw-processie van Doornik 
en het Vastenavondfeest zijn de twee grote constanten onder de feestelijkheden die wel telkens een behoorlijke hap uit het stedelijke budget nemen.

309. RIDER J. (ed.), Galbertus notarius Brugensis, De multro, traditione, et occisione gloriosi Karoli comitis Flandriarum, (Corpus Christianorum, Continuatio Mediaevalis, 13), Turnhout, 1994.

Nieuwe becommentarieerde tekstuitgave van de beroemde kroniek van Galbert van Brugge over de moord op graaf Karel de Goede in 1127 en de daaropvolgende moeilijkheden in het graafschap Vlaanderen.

310. SMALL G. en D. LIEVOIS, Les origines du chroniqueur George Chastelain (ca. 1414-ca. 1441), in Handelingen der Maatschappij voor Geschiedenis en Oudheidkunde te Gent, XLVIII, (1994), p. 121-177.

George Chastelain geniet vooral bekendheid als officiële kroniekschrijver van de Bourgondische hertogen Filips de Goede en Karel de Stoute. De meeste wetenschappelijke aandacht ging uit naar zijn literaire oeuvre, de neerslag van een bevoorrechte en onovertroffen getuige bij heel wat belangrijke $15 \mathrm{de}$-eeuwse gebeurtenissen. De auteurs van deze bijdrage gingen op zoek naar het curriculum van Chastelain en deden daarbij verrassende ontdekkingen, onder meer over zijn afkomst, zijn opleiding, zijn familiebanden, zijn militaire loopbaan, zijn verblijf in Gent en zijn relaties met het Gentse schippersmilieu, aspecten waarover de kroniekschrijver in zijn geschreven werk nauwelijks iets losliet. Met in bijlage tekstuitgaven van akten die in het bijzonder de band van Joris Castelain (alias George Chastelain) met Gent ondersteunen.

311. VANDE WALLE A., Wijn in Bourgondisch Vlaanderen, in Vlaanderen, 44, (1995), nr. 2, p. 35-37.

Beknopt overzicht van teelt, import en verhandeling van wijn in het middeleeuwse Vlaanderen, waarbij ook de rol van de havenkranen en de wijnschroders aan bod komt. Met enkele verwijzingen naar Gent. Geïllustreerd.

312. ZOETE A. ( $\uparrow)$, De beden in het graafschap Vlaanderen onder de hertogen Jan zonder Vrees en Filips de Goede (1405-1467), (Verhandelingen van de Koninklijke Academie voor Wetenschappen, Letteren en Schone Kunsten van België. Klasse der Letteren, nr. 149), Brussel, 1994, 275 blz. en microfiches.

Analyse van het middeleeuwse systeem van rechtstreekse staatsbelasting, op basis van een studie van rekeningen van centrale overheid, stad en kasselrij; dit systeem groeide uit tot één van de pijlers van de staatsfiscaliteit in de overgang van middeleeuwen naar moderne tijden. Met aandacht voor Gent dat, als één van de Vier Leden, een rem betekende voor de vorstelijke willekeur. Daarmee vormde Gent "als staat in de staat, de voor 


\section{CHARLES, R. DE HERDT, M.C. LALEMAN}

alles uit te schakelen tegenstrever op de weg naar het vorstelijk absolutisme". Met bibliografie, kritisch apparaat en bijlagen op microfiche.

\section{Moderne tijden}

313. COUCKE M.-T., A. DE BELIE en V. VERSTEGEN ( $\dagger$ ) (ed.), Liederboek van de Boudelo-abdij. Goddelijcke Lofsanghen door Gullielmus vander Machtelt, Monnik van Boudelo 1645-1661, (Culturele Kring Boudelo), Sint-Niklaas, 1995, $203 \mathrm{blz}$.

Anastatische herdruk van het liederenboek, met transcriptie en muzieknotatie in hedendaagse vorm. Geillustreerd.

314. DAMBRUYNE J., De Gentse bouwvakambachten in sociaal-economisch perspectief (1540-1795), in LIS C. en H. SOLY (ed.), Werken volgens de regels. Ambachten in Brabant en Vlaanderen 1500-1800, Brussel, 1994, p. 51-105.

Bijdrage rond de volgende kernpunten: welke ambachten zijn betrokken bij het bouwbedrijf, welke evolutie maken zij door, hoe groot was de mobiliteit binnen de bouwambachten, welke is de invloed van het kapitalisme binnen de bouwsector en hebben schaalvergroting en prolitarisering geleid tot meer sociale spanningen binnen het ambachtsmilieu ? Met een overzicht van de activiteiten van de verschillende bouwvakambachten, een uiteenzetting over het ambachtsbestuur en een uitgebreid kritisch apparaat.

315. DECAVELE J., Gentenaars Stropdragers, (Stadsarchief), Gent, 1995, 39 blz.

Rijk geîllustreerd relaas van een stad in opstand tegen Keizer Karel en van de beruchte afstraffing in 1540 die de Gentenaars voorgoed de naam van "stropdragers" bezorgde.

316. DECEULAER H., Stadsbestuur en buurtbewoners in Gent. Interactie, participatie, en publieke opinie, 1658-1668, in Bijdragen en mededelingen betreffende de geschiedenis der Nederlanden, 110, (1995), nr. 1, p. 3-26.

Vernieuwende bijdrage over de wijze waarop de Gentse bevolking politieke inspraak verwerft nadat de Carolijnse Concessie (1540) haar nagenoeg monddood had gemaakt. Via de organisatievorm van het gebuurte is er sprake van een wederzijdse beïnvloeding van volk en bestuur en van reële invloed van het volk op de politieke besluitvorming. Onderwerp bestudeerd aan de hand van drie gebieden waarop de invloed van het gebuurte en van het bestuur zeer duidelijk is: het bemiddelen in conflicten, de armenzorg en de misdaadbestrijding. Publieke opinie en geroddel blijken van belang te zijn bij het tot stand komen van een consensus. De auteur baseert zich vooral op de dagelijkse notities van de 
Gentse politiemeester en schepen Justus Billet, actief tussen 1658 en 1668.

317. DE NAVE F., C. DEPAUW e.a., Europa aan tafel. Een verkenning van onze eet- en tafelcultuur, Antwerpen, 1995, 239 blz.

Waarin o.a. C. TERRYN de achttiende-eeuwse Gentse tafelmanieren beschrijft.

318. JELSMA A.J. en O. BOERSMA (ed.), Acta van het consistorie van de Nederlandse gemeente te Londen 1569-1585, 'S Gravenhage, 1993, XXXVI en 869 blz.

De Nederlandse vluchtelingenkerk te Londen fungeerde als voorbeeld voor de organisatie en de structuur van het kerkelijke leven in die gewesten die zich aan de Spaanse heerschappij onttrokken hadden. Het overzicht van de voornaamste predikanten wordt gevolgd door de integrale transcriptie van de tekst van de acta. Bevat tal van verwijzingen naar vluchtelingen uit Gent. Met glossarium en uitgebreide index op personen, plaatsen en zaken. Geillustreerd.

319. GISTELINCK F. en M. SABBE (ed.), Early Sixteenth Century Printed Books 1501-1540 in the Library of the Leuven Faculty of Theology, Leuven, 1994, XXII en 567 blz.

De catalogus, samengesteld door F. GISTELINCK, bevat 901 nummers en vermeldt diverse Gentse drukken, onder meer afkomstig uit de het klooster van de Bijloke en uit de bibliotheek van de Gentse Societas Jesu. Met uitgebreide indices op drukkers, boekverkopers, uitgevers en medewerkers van drukkers. Rijk geïllustreerd.

320. Hoe zien vreemdelingen Gent?, in Ghendtsche Tydinghen, 24, (1995), nr. 1, p. 42-43.

Reisaantekening uit 1790 over de barge en over Gent door de ontdekkingsreiziger, Georg Foster $\left({ }^{\circ} 1754-\dagger 1794\right)$.

321. LENDERS P., Nota betreffende de collocatie op verzoek in het achttiendeeeuwse graafschap Vlaanderen, in Handelingen der Maatschappij voor Geschiedenis en Oudheidkunde te Gent, XLVIII, (1994), p. 193-196.

In een beknopte notitie formuleert de auteur zijn kritiek op de publikatie van C. LIS en H. SOLY, Te gek om los te lopen? Collocatie in de 18de eeuw, Turnhout, 1990. Hij verwijst daarbij vooral naar tussenkomsten van raadsheer Goswin de Fierlant en van Jean Jacques Philippe Vilain XIIII die in Gent vooral bekend is als politicus en auteur van belangrijke publikaties.

322. LIS C., en H. SOLY, Collocatie en verlichting in de Oostenrijkse Nederlanden, in Handelingen der Maatschappij voor Geschiedenis en 


\section{CHARLES, R. DE HERDT, M.C. LALEMAN}

Oudheidkunde te Gent, XLVIII, (1994), p. 197-200.

In deze notitie wordt de kritiek van P. LENDERS (zie sub LENDERS P.) op hun publikatie Te gek om los te lopen? Collocatie in de 18de eeuw (Turnhout, 1990) geëvalueerd en in een ruimer historisch perspectief gesitueerd.

323. SWART K.W. $(\dagger)$, Willem van Oranje en de Nederlandse Opstand 15721584, Den Haag, 1994, 311 blz.

Posthume publikatie, met kritisch apparaat, overzicht van archieven, bibliografie en pamfletten. Geîllustreerd.

324. TAVERNE E. en I. VISSER (ed.), Stedebouw. De geschiedenis van de stad in de Nederlanden van 1500 tot heden, Nijmegen, 1993, $394 \mathrm{blz}$. Synthesewerk over stadsgeschiedenis. Bijdragen van M. RYCKAERT, Stad, tijd en landschap (p. 45-49), R. FABRI, Het Vlaamse stadsbeeld in de 16de en 17de eeuw (p. 72-77), P. DEVOS, Tussen "hôtel" en "cité ouvrière" (p. 142-147), H. BALTHAZAR, Deopkomst van een moderne industriële staat (p. 180-183) en van M. DUBOIS, "Revalorisatie" van het stedelijk landschap (p. 213-217). Met vermelding van het hotel D'Hane-Steenhuyse, de vele beluiken, het Zollikofer-De Vigne-plan en woontorens aan de Watersportbaan. Geillustreerd.

325. VANDENBROEKE C., De lokalisatie van het publikatieaanbod in de Zuidelijke Nederlanden op basis van de van Hulthem-bibliotheek(15debegin 19de eeuw), in Handelingen der Maatschappij voor Geschiedenis en Oudheidkunde te Gent, XLVIII, (1994), p. 179-192.

In 1836 werd de beroemde bibliotheek van Charles Van Hulthem geveild. Hij stond als een uitnemend bibliofiel bekend en de veilingcatalogus omvat zowat 32.000 nummers en 60.000 volumes. De bijdrage gaat in op het percentage dat de Zuidnederlandse publikaties daarin vertegenwoordigden en over de evolutie van dat aandeel ten opzichte van andere tussen de late $15 \mathrm{de}$ en het begin van de 19de eeuw. Binnen dat aandeel worden ook de verhoudingen tussen de verschillende steden, waaronder Gent, nader ontleed.

326. VAN GELDEREN M. (ed.), The Dutch Revolt, (Cambrigde texts in the history of Political Thought), Cambridge, 1993, XLVIII en 250 blz. Engelse tekstuitgave van vijf documenten uit de periode 1570-1587 die moeten gelezen worden als onderbouw van het verzet tegen de regering van Filips II. Gent komt ter sprake bij de analyse van de Pacificatie van Gent (1576) Address and Opening to make a good, blessed and general peace in the Netherlands ... (p. 79-122). Met chronologisch overzicht, een bibliografie, kritisch apparaat en biografische notities over de protagonisten. 
327. VAN WERVEKE A., De plechtige intrede van Generaal Van der Meersch te Gent, in Ghendtsche Tydinghen, 24, (1995), nr. 1, p. 38-41.

\section{Hedendaagse tijd}

328. CAPITEYN A. (red.), Interbellum in Gent 1919-1939, (Stad Gent, Stadsarchief en Museum Arnold Vander Haeghen), Gent, 1995, 223 blz. Een gevarieerde reeks opstellen over het leven, de gebeurtenissen, het stadsbeeld, kunst en cultuur in Gent in de periode tussen beide wereldoorlogen. Met bijdragen van D. DE WEERDT, L. FRANCOIS, G. DENECKERE, E. LANGENDRIES, A.M. MUSSCHOOT, N. POULAIN, A.M. DE COCK en G. DESEYN. Geïllustreerd.

329. COPPEJANS-DESMEDT H., Bevolking en tewerkstelling in transformatie op het Vlaamse platteland (einde 18de-midden 19de eeuw), in Het Tijdschrift van het Gemeentekrediet, 48, (1994), nr.4, p.15-34.

In de overgang van agrarische naar industriële maatschappij wordt eerst te Gent de mechanisatie in de katoenindustrie geintroduceerd. Landbouw en linnennijverheid zijn de voornaamste bronnen van inkomsten op het omliggende platteland. De invloed van de industrialisering op het platteland blijkt een eerder onevenwichtig proces te zijn geweest, dat alleen door lokale detailstudies zal kunnen in kaart worden gebracht. Midden 19de eeuw is de polarisatie arm-rijk een feit. De industriële burgerij telt haar winsten terwijl de meerderheid van de bevolking onder armoede gebukt gaat. De auteur maakt onder meer gebruik van het bedrijfsarchief "A. Voortman - NV Texas" uit het Gentse Stadsarchief.

330. DE BAETS H., Militaire post tijdens de oorlogsjaren te Zwijnaarde, in Heemkring Scheldeveld. Jaarboek, XXIII, (1994), p. 121-139.

331. DE DECKER, P., Een geografische kijk op het wonen in Vlaanderen, in Het Tijdschrift van het Gemeentekrediet, XLVIII, (1994), nr. 190, p. 3556.

Met vermelding van Gent.

332. DENECKERE G., Burgerrechten, collectieve actie en staatsvorming. Gent 1830-1839, in Bijdragen en Mededelingen betreffende de Geschiedenis der Nederlanden, 110, (1995), nr. 2, p.182-204.

De invloed van de collectieve actie op het staatsbestel wordt aangetoond met voorbeelden van petities en demonstraties uit Gent in de turbulente periode 1830-1839. Deze betekende de basis van het staatsinitiatief om de Gentse katoenindustrie te beschermen tegen buitenlandse concurrentie en via de bankwereld te subsidiëren. Met in bijlage: Petitie van de Gentse katoenarbeiders aan de koning, december 1839. 


\section{CHARLES, R. DE HERDT, M.C. LALEMAN}

333. DENECKERE G., Turbulentie rond de vernederlandsing van de Gentse universiteit na de Eerste Wereldoorlog. Analyse van een besluitvormingsproces, in Handelingen derMaatschappij voor Geschiedenis en Oudheidkunde te Gent, XLVIII, (1994), p. 201-231.

Studie met speciale aandacht voor de buitenparlementaire acties tijdens het Interbellum; uitgangspunt voor het conflict is de belofte van vernederlandsing door Albert I uitgesproken tijdens de troonrede van 1918. De strijd wordt gevoerd, niet door de flaminganten, maar wel door de Franse tegenpartij (1922-1923).

334. D'HOKER M., R. RENSON en J. TOLLENEER, Katholieken, lichamelijke opvoeding en sport in de 19de en 20ste eeuw, (Kadoc-Studies, $n r$. 17), Leuven, 1994, 293 blz. Geillustreerd.

DeGentse situatie komt vooral ter sprake in twee bijdragen: M.D'HOKER, Lichamelijke opvoeding in het katholiek onderwijs: een lange weg, een moeilijk parcours (p. 43-97) en bij R. RENSON, Corpus Alienum: naschoolse sport in het katholiek onderwijs (p. 99-121). Met uitgebreide bibliografie, biografisch repertorium en index van plaatsnamen en corporaties.

335. DHONDT L., Plattelandslijnwaad en stadskatoen tegen en even na 1900. De organisatie van een oude en van een nieuwe industrie. Een memorie uit 1808 en haar relevantie, in Handelingen van de Geschieden Oudheidkundige Kring van Oudenaarde, XXXII, (1995), p. 89-149. Waarin een aantal gegevens over de eerste industriële revolutie te Gent. Met kritisch apparaat. Geillustreerd.

336. HEMMERIJCKX R., A la guerre comme à la guerre. Gentse socialisten tussen collaboratie en verzet (1940-1944), in Belgisch Tijdschrift voor Nieuwste Geschiedenis, XXIV, (1993), nr. 3-4, p. 529-568.

De opheffing van de Belgische Werkliedenpartij door Hendrik de Man en de publikatie van zijn Manifest in 1940, zette de deur open voor openlijke collaboratie met de bezetter. Vlaanderen, en vooral Gent, volgde hem hierin moeiteloos maar de rol van het V.N.V. binnen de organisaties neemt hand over hand toe. Vanaf 1941 komt binnen socialistische middens, de mutualiteiten, de corporaties en de vakbonden, toch ernstig verzet op gang, onder meer onder impuls van Eduard Anseele. Het defensief gericht socialistisch verzet hield zich vooral bezig met de verspreiding van sluikbladen, met de financiële ondersteuning van werkweigeraars en ondergedoken militanten via de dienst Socrates en met de voorbereiding van de partijwerking na de oorlog. Een zuivering van de partij vond plaats na de oorlog en een nieuwe politieke generatie, geboren uit het verzet, nam het voortouw in de wederopbouw van de partij. 
337. HEYRMAN P., S. JAUMAIN en G. VANTHEMSCHE, De middenstandsorganizaties en de gemeenteverkiezingen in vijf Belgische steden (1895-1952), in Belgisch Tijdschrift voor Filologie en Geschiedenis, LXXII, (1994), nr. 2, p. 311-380.

Met vermelding van Gent.

338. PALINCKX K., "Nu naar Gent!" Vlaams-nationale en katholieke studentenbeweging te Gent 1928-1940, (Uit het verleden van de RUG, $n r$. 38), Gent, 1995, $316 \mathrm{blz}$.

Publikatie van een licentiaatsverhandeling, met aandacht voor de geschiedenis van het Algemeen Vlaams Hoogstudenten Verbond, het Gents Studenten Corps, het Vlaams Nationaal Verbond en het Katholiek Vlaams Hoogstudenten Verbond. Met kritisch apparaat en bibliografie.

339. PAUWELS W., De bevrijdingsdagen van 1944. De geheime rapporten van François Louis Ganshof, Antwerpen, 1994.

Bespreekt de wijze waarop de collaborerende Vlamingen en Walen gevangen genomen zijn en berecht en de waardering voor het optreden van de weerstandsorganisatie tijdens en onmiddellijk na de bevrijding. Van belang voor West- en Oost-Vlaanderen, ook voor Gent.

340. PITTOMVILS K., Alledaagse arbeidsconflicten in de Gentse textielindustrie. De praktijk van de werkrechtersraad in de eerste helft van de negentiende eeuw, in Tijdschrift voor sociale geschiedenis, 21, (1995), nr. 2, p. 181-211.

Studie van het belang van de werkrechtersraad waarvan de oprichting in 1810 moet gezien worden als een middel om sociale spanningen en economische moeilijkheden tussen katoenproducenten en hun werknemers en tussen de eersten en de huiswevers op te lossen.

341. SCHOLLIERS P., Grown-ups, boys and girls in the Ghent cotton industry: the Voortman mills, 1835-1914, in Social History, (1995), nr. 2, p. 203-218.

Lage lonen en het grote aantal vrouwelijke arbeidsters gingen hand in hand in de Gentse textielsector. Vrouwen waren daardoor gedwongen loonarbeid te verrichten zolang de kinderen te jong waren om een deel van het gezinsinkomen op zich te nemen. Eerst na de Eerste Wereldoor$\log$ zou hierin verandering komen.

342. VAN DER HERTEN B. en M. VAN MEERTEN, De spoorlijn Antwerpen-Gent, 1841-1897. De wisselwerking tussen privé-initiatief en overheidsinterventie in de Belgische spoorwegen, in Belgisch Tijdschrift voor Filologie en Geschiedenis, LXXII, (1994), p. 861-912. 


\section{CHARLES, R. DE HERDT, M.C. LALEMAN}

343. VANHAUTE E., "De meest moordende van alle industrieën". De huisnijverheid in België omstreeks 1900, in Tijdschrift voor Sociale Geschiedenis, 20, (1995), nr. 4, p. 461-483.

Met vermelding van Gent.

344. VANSCHOENBEEK G., Van armenzorg naar sociale zekerheid: een brok geschiedenis in vogelvlucht, in AMSAB-Tijdingen, (1995), nr. 27, p. 4-14.

Bevat tevens een kroniek van de cruciale data in de uitbouw van de wetgeving terzake en een bibliografisch overzicht.

345. VANSCHOENBEEK G., Novecento in Gent. De wortels van de sociaaldemocratie in Vlaanderen, Gent, 1995, 269 blz.

Samenvatting van doctoraatsverhandeling (1992). Drieluik met een chronologisch relaas van de opkomst en doorbraak van het socialisme in Gent vooral onder impuls van Eduard Anseele, gevolgd door een uiteenzetting over de uitbouw van de rode "zuil" rond de eeuwwisseling en tenslotte verhalen over het leven van een reeks militanten. Het namenregister verleent toegang tot deze levensbeschrijvingen. Het ontbreken van bibliografie en kritisch apparaat beperkt evenwel het wetenschappelijk nut van dit werk. Geillustreerd, met namenregister.

346. WILS L., Vlaanderen, België, Groot-Nederland. Mythe en Geschiedenis. Historische opstellen, gebundeld en aangeboden aan de schrijver bij het bereiken van zijn emeritaat als hoogleraar aan de K.U. Leuven, Leuven, 1994, 501 blz.

Betreffende Gent zijn vooral van belang: De verhouding tussen Vlaamse beweging en arbeidersbeweging in Gent (p. 175-196) en Tussen taalstrijd en arbeidersbeweging: de Onafhankelijke Volkspartij in de jaren 1860 (p. 197-227).

Industriële Archeologie

347. BOGAERTD., Stedelijke milieuhinderin de pre-industriële tijd(18de en begin 19de eeuw), in Tijdschrift voor Industriële Cultuur, 13, (1995), nr. 3, p.18-35.

Behandelt de vervuiling van straten en waterwegen en de verontreiniging door diverse bedrijfstakken: de textielindustrie, de suikerraffinaderijen, de stokerijen en de bierbrouwerijen. Geillustreerd.

348. COLLUMBIEN H., De "puntfabriek", in Ghendtsche Tydinghen, 24, (1995), nr. 4, p. 216-220.

Bedrijfsgeschiedenis van de "Clouterie et Tréfilerie des Flandres", in 1953 geïntegreerd bij ARBED. 
349. DE HERDT R., De Gentse sierteelt in de 19de en begin 20ste eeuw, in Tijdschrift voor Industriële Cultuur, 13, (1995), nr. 2, p. 3-11.

350. DESEYN G., "Genaemd de Waeterwijck". Industrieel-archeologische sprokkels uit de geschiedenis van de wijk Sluizeken-Muide-Ham, in Tijdschrift voor Industriële Cultuur, 13, (1995), nr. 1, p. 3-11. Met voetnoten.

351. DESEYN G. en G. VERHEEKE, Net geen veertig jaar. Interview met Albert Warie, langst tewerkgesteld in de Gentse filmexploitatie: van 1939 tot 1979, in Tijdschrift voor Industriële Cultuur, 13, (1995), nr. 3, p. 317. Geillustreerd.

352. SACHTLEBEN V., Der flämische und der deutsche Gründer der Chemischen Fabrik Curtius in Duisburg, in Duisburger Forchungen, 41, (1995), p. 121-134.

353. SERRUS B., K. PITTOMVILS en S. MENGE, Gestrand in 't Seles Kest. Verhalen uit de Minnemeers, in Tijdschrift voor Industriële Cultuur, 13, (1995), nr. 1, p. 12-39.

De weergave van een veertiental interviews met oudere bewoners uit de Minnemeerswijk. Geilllustreerd.

Kerkgeschiedenis, kloosters

354. BERINGS G., Op gespannen voet. Cluny in het Graafschap Vlaanderen, in Vlaanderen, 44, 1995, nr. 2, p. 12-14.

De auteur situeert de stichting van de Bourgondische abdij Cluny in 909 ten opzichte van de toenmalige kloosters en de oudere kloosterhervormingen. Hij gaat in op de inhoud van het monastieke leven en de organisatie waardoor Cluny een grote verspreiding kende in de 10de11 de eeuw. In het graafschap Vlaanderen kreeg deze hervormingsbeweging geen vaste voet. Via de Sint-Bertijnsabdij van Saint-Omer werden de Cluniacenzerideeën toch in enkele Vlaamse abdijen geïntroduceerd zoals in de Gentse abdijen van Sint-Pieters en Sint-Baafs, maar na korte tijd ebde die invloed reeds weg. Geillustreerd.

355. CASSIMAN P., Een halve eeuw Congregatie der Jonge Dochters te Baarle (1850-1903), in Dronghine. Jaarboek, (1995), p. 3-7.

Overzicht van de geschiedenis van de Congregatie op basis van het "Beraadslag- en Rekenboek der Congregatie, van de jonge Dochters, ingericht te Baerle, onder den titel van de Hemelvaart der Allerheiligste Maagd en Moeder Gods Maria, den 16 julij 1850", bewaard in het archief van de Sint-Martinuskerk te Baarle. 
356. LOUIS E., L'ancienne abbaye de Hamage à Wandignies-Hamage ( $F$, 59), in Archaeologia Mediaevalis, 18, (1995), p. 20-23.

De bondige kroniektekst geeft de eerste onderzoeksresultaten van archeologisch onderzoek op de plaats waar in het midden van de 7de eeuw een dubbelklooster werd opgericht. Deze bevindingen overstijgen het lokale belang, niet in het minst omwille van de inzichten van de organisatie, de structuur en de huisraad van het vroeg-middeleeuwse klooster. Voor het eerst krijgt men een duidelijk beeld van een klooster zoals ze er mogelijk ook in het Gentse uitzagen vóór de hervormingen van de 9de eeuw. De uitzonderlijke conserveringstoestand van de materiële resten in Hamage leidde er tot resultaten die elders niet meer mogelijk zijn omwille van de te fragmentarisch bewaarde relicten.

357. MAES D., Gentenaars als abt van "Ter Duinen" te Koksijde, in Ghendtsche Tydinghen, 24, (1995), nr. 2, p. 96-97.

358. SCHEEPSMA W.F., Van die memorie der passien van Alijt Bake, in Ons Geestelijk Erf, 68, (1994), afl. 1-2, p. 106-128.

Alijt Bake, priorin van het Windesheimse vrouwenklooster Galilea te Gent, is de auteur van verschillende mystieke geschriften. Eén daarvan Van die memorie der passien (UG, 3854) is een bevattelijke synthese van haar Hemelvaartsvisioen dat eerder verwoord werd in Mijn beghin ende voortganck. Het geestelijk samenzijn met Christus doorloopt drie wegen: het gedenken van het lijden, het mede-lijden en het loslaten van de individuele eigenheid. In 1455 werd zij afgezet en verbannen, wellicht omdat haar streven naar innerlijke mystiek niet strookte met de leer van de praktische deugdzaamheid. Tekstuitgave met kritisch apparaat.

359. STOCKMAN L., Schenking van een stuk grond te Lovendegem aan het Sint-Elisabethbegijnhof te Gent (1305), in Appeltjes van het Meetjesland. Jaarboek, 45, (1994), p. 101-104.

360. STOCKMAN L., Het testament van Jacob de Donker, pastoor van Ter Piet in het Ambacht Boekhoute (1331), in Appeltjes van het Meetjesland. Jaarboek, 45, (1994), p. 201-211.

361. TISSEGHEM R. en J. DAEMEN, Begijnhoven vroeger en nu "Neerstigh tot eere Godts", Groot-Bijgaarden, 1994, $237 \mathrm{blz}$ Met vermelding van Gent.

362. VANDEN BROECKE S., Seculiere geestelijken in het 17de-eeuwse bisdom Gent: een prosopografie, in Trajecta, 3, (1994), afl.3, p. 193-208. Prosopografische studie van de seculiere geestelijkheid aan de hand van de computer. De auteur onderzoekt het milieu waaruit deze geestelijken worden gerecruteerd en hun loopbanen in de parochies. 
363. VAN DE PERRE N., De datum van de bisschopswijding van Nikolaas van Chievres (1136-1167) en de gevolgen voor de datering van zijn oorkonden, in Het Land van Aalst, XLVII, (1995), nr. 2, p. 143-155. Naar aanleiding van de publikatie in C. VLEESCHOUWERS, De oorkonden van de Sint-Baafsabdij 819-1321, (Koninklijke Academie van België, Koninklijke Commissie voor Geschiedenis), Brussel, 1990, van twee oorkonden van de Sint-Baafsabdij, nl. over het patronaat van de kapel van Landskouteren over de schenking van de kapel van Gentbrugge.

364. WITDOUCK R., Kapittels en Kanunniken onder Philips d'Arbois, bisschop van Doornik (1351-1378), in De Leiegouw, XXXVII, (1995), nr. 2, p. 115-194.

Besteedt aandacht aan het Sint-Veerlekapittel in Gent en behandelt achtereenvolgens de kerk, het kapittel, de proosten en de dekens (p. 185 192).

\section{Gebouwen, monumenten, stadsbeeld}

365. 100 Jaar leven in de brouwerijschool Sint-Lieven 1892-1992, Gent, 1995, 327 blz.

Jubileumboek met historische bijdragen over het brouwersambacht te Gent en over ontstaan en bloei van de school vooral onder impuls van Gabriël Van den Gheyn (1892-1907). Opstellen van: H. BUTAYE, Jakob Van Artevelde: brouwer of volkstribuun (p. 26-30); ID., Merkwaardige resten van ons brouw-verleden (p. 31-42); ID., Sint-Lieven: schutsheilige of twistappel (p. 53-57); J. VAN DE WIELE, Van monnikenwerk en ambacht tot grootindustrie of ... de geschiedenis van het brouwen te Gent (p. 16-25). Rijk geïllustreerd en voorzien van een bibliografie.

366. ADRIAENSSENS I., Gebouwen om naar te luisteren. Veertig Vlaamse monumenten met muziekgeschiedenis, Tielt, 1994, 264 blz.

Bijdragen over Gentse gebouwen: het Bijlokehospitaal, de SintBaafskathedraal en de Vlaamse Opera. Geillustreerd.

367. BAUTERS L. en M.C. LALEMAN, De kerk van de geschoeide karmelieten. Beschouwingen bijeen dakonderzoek, in Stadsarcheologie. Bodem en monument in Gent, 18, (1994), nr. 2, p. 35-40.

De auteurs gaan dieper in op de dendrochronologische resultaten met betrekking tot de dakconstructie boven de tweede beuk van de voormalige Karmelietenkerk (zie HOFFSUMMER P. en D. HOUBRECHTS). De datering 1520-1530 kan in verband gebracht worden met de uitbreidingsfase van de kerk waarin de tweede beuk en de zuidelijke zijkapellen opgetrokken werden. De bouwfase met 1583 als terminus post quem duidt wellicht op herstellingen of een verbouwing in de Contrareformatieperiode. Geilllustreerd. 
368. BAUTERS L., M.C. LALEMAN, A.LENS, D. LIEVOIS en G. STOOPS, Het klooster van de Geschoeide Karmelieten in Gent (O.Vl.), in Archaeologia Mediaevalis, 18, (1995), p. 25-26.

Beknopt overzicht van wat het archeologisch onderzoek in 1994 aan resultaten bijbracht voor de geschiedenis en de bouwkundige ontwikkeling van dit kloostercomplex en met duidingen over diverse types van bijzettingen, waaronder beschilderde grafkelders, die in de kerk aan het licht kwamen.

369. BAUTERS L. en I. VAN DRIESSCHE (red.), Archeologie en cultuurtoerisme, (Provinciebestuur Oost-Vlaanderen), Gent, 1995, 74 blz.

Deze uitgave, bij gelegenheid van een studiedag in Oudenaarde over het thema 'Archeologie en cultuurtoerisme', verzamelt enkele bondige bijdragen over de impact van cultuur in de ontwikkeling van het toerisme, over de betekenis van archeologisch erfgoed in de evolutie van het cultuurtoerisme en over de ontsluiting van archeologische sites voor toerisme. Ervaringen, voornamelijk uit de provincies Zeeland, West- en Oost-Vlaanderen, ondersteunen de uiteenzettingen. De inspanningen van de Provincie Oost-Vlaanderen op het vlak van archeologische patrimoniumzorg en cultuurtoerisme werden in het bijzonder beklemtoond. Doch ook in andere bijdragen kwamen inzichten en ervaringen aan bod die ook voor het Gentse archeologisch en monumentaal erfgoed van betekenis zijn. Gent ontbrak uiteraard niet bij de opgave van de potentiële archeologische objecten in de provincie Oost-Vlaanderen (p. 24). Met vooral verwijzing naar de bijdragen van L. DECAUTER, N. VANHOVE, U. CLAEYS, J. HENDRIKS, E. VAN GINKEL en A. DE KLERK.

370. BEKAERT G. en M. DUBOIS (red.), Jaarboek Architectuur Vlaanderen 1990-1993, (Ministerie van de Vlaamse Gemeenschap), Brussel, 1994, 224 blz.

$\mathrm{Na}$ de inleidende teksten van de vermelde auteurs over respectievelijk 'Architectuur, parasiet of maatschappelijke noodzaak' en de toelichting over de opzet van het jaarboek, volgens zeven essays rond hedendaagse architectuur. Daarvoor tekenden M. SMETS, F. STRAUVEN, P. UYTTENHOVE, A. LOECKX, G. PAULISSEN, E. LAGROU en F. DE PAU. Bij het dertigtal projecten dat meer in detail wordt toegelicht vindt men voor Gent het UCO-gebouw (Bellevue), de woning Speeckaert (Jacob van Maerlantstraat) en de herstructurering van een 19de-eeuws pand (Kouter) terug. De publikatie wordt afgesloten met een overzicht van architectuurprijzen, tentoonstellingen, publikaties en met samenvattingen in het Frans en het Engels. Geillustreerd.

371. Beschermde monumenten, stads- en dorpsgezichten, in Kultureel Jaarboek voor de Provincie Oost-Vlaanderen, 47, (1993), p. 161-196.

In 1993 werden voor Gent beschermd: de huizen gelegen in de Sint- 
Kathelijnestraat 8 en 10-12, met de aanpalende panden in de Goudstraat en Gelukstraat, een huis gelegen Kunstlaan 41, het voormalig textielbedrijf Van Acker, Bachtenwalle 1, het Sint-Veerleplein en omgeving (deel van de Burgstraat, de Jan Breydelstraat en het Vleeshuisstraatje), en de Hoeve Dossche, Woestijnegoedlaan 14 en hoevetje aan de Vroonstalledries 66 te Wondelgem.

372. BOHEZ R., C. DE SUTTER en G. VAN DOORNE, Verdwenen hoekjes van het oude Gent. Uit de fotoverzameling van de Commissie van Monumenten en Stadsgezichten, Gent, 1994, z. blz.

Selectie uit de fotoverzameling.

373. CHARLES L., R. K. DEBRUYNE, J. DECAVELE, G. EVERAERT, M.C. LALEMAN, D. LIEVOIS en R. VANDEN BILCKE, Huizenonderzoek in Gent. Een handleiding, (Stadsarchief), Gent, 1994, 127 blz. Methodologische uiteenzetting over het huizenonderzoek van het Gentse particuliere woonhuis. Met de volgende bijdragen: Van materieel spoor tot huizengeschiedenis (M.C. LALEMAN, p. 7-20), Een nieuwe methode voor het bouwhistorisch onderzoek van particuliere huizen in Gent en De landcijnsboeken in Gent (D. LIEVOIS, p. 21-25, p. 29-35), De registers van het huisgeld (L. CHARLES, p. 37-59), Het kadaster, Het Frans kadaster per soort van grondgebruik, Het Frans parcellair kadaster, Het Hollands kadaster en Systematiek van het huizenonderzoek in Gent (D. LIEVOIS, p. 61, p. 63-65, p. 67-73, p. 75-79, p. 117-122), Het Belgisch kadaster (R. VANDEN BILCKE, p. 81-94), Registratie en hypotheken (R.K. DEBRUYNE, p. 95), Bronnen voor bouwhistorisch onderzoek in Gent (J. DECAVELE, p. 97-112) en Gebruik van het bouwhistorisch onderzoek - een evaluatie (G. EVERAERT en M.C. LALEMAN, p. 123-125).

374. COLLEN-JANSSENS J., Gentse parken en groenzones. 1. Het Zuidpark, in G.O.V. Heraut, 30, (1995), nr. 1, p. 1-18.

375. DAMBRUYNE J., Stadsambtenaren betrokken bij de Gentse bouwsector tijdens het Ancien Régime, in Handelingen van het Lle Congres van de Federatie van Kringen voor Oudheidkunde en Geschiedenis van België, Liège, 1994, nr. 2, p. 378-391.

Aan de hand van concrete voorbeelden voor de periode $16 \mathrm{de}-18 \mathrm{de}$ eeuw gaat de auteur dieper in op de functie, het werk en de inkomsten van bouwvakkers met officiële opdracht. Behalve algemene gegevens betreffende deze bouwlui, komen de erfscheiders, de ontvangers en de commissarissen van de stadswerken, de politiemeesters, de houtmeters, de kalklossers en de keurders van de rode aarde in dit beknopte overzicht aan bod. 
376. DECAVELE J. en U. VANWILDEMEERSCH, Bachte-Maria-Leerne. Dubbeldorp, in Toerisme Oost-Vlaanderen, 44, (1995), nr. 2, p. 14-16. Historische schets van de kerken, het kasteel en van het dorp dat ontstond uit een samenvoegen van Sint-Maria-Leerne met Bachte.

377. DE PERMENTIER C., Via Florea (1): een wandeling langs Oostvlaamse Sierteelt, in G.O.V. Heraut, 30, (1995), nr. 1, p. 1-4.Zie ook ID., Via Florea (2): een wandeling langs Oostvlaamse Sierteelt. De Azalea Gloria Gandavensis, in G.O.V. Heraut, 30, (1995), nr. 2, p. 5-12; Via Florea (3): Orchideeën, de Fine Fleur van de Bloementeelt, in G.O.V. Heraut, 30, (1995), nr. 3, p. 13-19; Via Florea (4): een wandeling langs de Oostvlaamse Sierteelt. De Begonia, de koningin der bloemtapijten, in G.O.V. Heraut, 30, (1995), nr. 4, p. 21-30 en Via Florea (5): De Roos, in G.O.V. Heraut, nr. 5, p. 31-38..

378. DEROM S., Gravensteen. Een bezoek aan het Gravensteen, (Dienst Monumentenzorg), Gent, 1995, 31 blz.

Beknopte historiek van het Gravensteen, van de grafelijke residentie, over particulier gebruik als katoenspinnerij naar de ontmanteling en de restauratie. Geïllustreerd.

379. DEROM S., Het huis Voortman te Gent, een prachtige directeurswoning in Empire-stijl, in De Woonstede door de eeuwen heen, 106 (1995), p. 215 .

Het betreft een gedocumenteerde bijdrage over het huis dat de bekende textielindustrieel Abraham Voortman aan Vogelenzang had gepland. Het werd in 1816 naast het grote bedrijf in opdracht van zijn weduwe opgetrokken. Het ontwerp, waarnaar enkele recent ontdekte tekeningen eveneens verwijzen, wordt toegeschreven aan architect Jean-Baptiste Pisson (1763-1818), wiens oeuvre beknopt wordt toegelicht. De bijdrage geeft niet alleen de bouwgeschiedenis en gegevens over de familie Voortman, die de eigendom bijna twee eeuwen koesterde, maar biedt tevens een kleurrijk inzicht in de woning, de interieurs en de prachtige tuin die het buitenhuis omringde. Geîllustreerd.

380. DE SUTTER C. en G. VAN DOORNE, Verdwenen hoekjes van het oude Gent uit de fotoverzameling van de Commissie van Monumenten en Stadsgezichten, (Koninklijke Dekenij Patershol v.z.w.), Gent, 1995, z. blz., $147 \mathrm{afb}$.

Tweede uitgave van een reeks archieffoto's uit de rijke verzameling van de Stedelijke Commissie voor Monumenten en Stadsgezichten. Met plaatsnamenregister. Geillustreerd.

381. DEVRIESE L., Enkele bouwblokken in de Gentse Waterwijk. Evolutie van het huizenbestand sinds het einde van de 17de eeuw, in Stads- 
archeologie. Bodem en monument in Gent, 19, (1995), nr. 1, p. 7-22. Aan de hand van kadastrale en fiscale gegevens ondernam de auteur een grondige studie naar de ontwikkeling van de bebouwing tussen 1672 en 1810-1813 voor drie bouwblokken binnen de Waterwijk, tussen de Ottogracht en de Minnemeers. In de studie worden ook enkele verwijzingen naar vroegere toestanden, oudere bronnen en meer recente ontwikkelingen opgenomen. Met reconstructieplannen en overzichtstabellen.

382. DEVRIESE L., De Gentse Waterwijk. Een ghebuerte uit het Ancien Régime, in Stadsarcheologie. Bodem en monument in Gent, 19, (1995), nr. 1, p. 5-6.

Over de oppervlakte en de begrenzing van het stedelijke deelgebied dat als Waterwijk wordt aangeduid, bestaat geen eensluidende visie. Aan de hand van enkele bronnen uit de 16de-17de eeuw geeft de auteur een precieze omschrijving.

383. DUBOIS M., Belgio. Architettura, gli ultimi vent'anni, (Tendenze del l'architettura contemporanea), Milano, 1993, $166 \mathrm{blz}$.

Met de internationaal bekende Art Nouveau-architectuur van Victor Horta en Paul Hankar als uitgangspunt wordt een beeld gegeven van kwaliteitsvolle hedendaagse architectuur in België. Het geheel is in verscheidene hoofdstukken rond gekozen themata opgedeeld en behandelt onder meer de relatie stedebouw/architectuur, naast beknopte overzichten voor Vlaanderen en Wallonië. In een tweede gedeelte worden een aantal werken uit de periode na 1965 meer in detail toegelicht. Bij het rijk geîllustreerde voorbeeldengamma komt ook werk aan bod van Gentse architecten en architecten die in Gent werkzaam zijn. Wat gebouwen in Gent betreft wordt er onder meer aandacht geschonken aan de Noordstargebouwen (Groot-Brittanniëlaan), het Huis Cleyman en het winkelpand Negozio Queen's. Geîllustreerd.

384. DUBOIS M., Het eerste art nouveaugebouw in Gent. Woning Delacre van architect Octave Van Rysselberghe 1897, in Jaarboek 1992-1993 Hoger Architectuurinstituut Sint-Lucas, (Centrum voor Architectuuronderzoek), z. pl., 1994, p. 38-47.

Studie gewijd aan de woning van professor Maurice Delacre gelegen aan de Fortlaan, het eerste volwaardige Art Nouveau-gebouw te Gent, ontworpen door de Gentse architect Van Rysselberghe.

385. HOFFSUMMER P en D. HOUBRECHTS, De Karmelietenkerk in Gent. Dendrochronologische analyse van de dakconstructie boven de tweede beuk, in Stadsarcheologie. Bodem en monument in Gent, 18, (1994), nr. 2, p. 29-34.

De dendrochronologische studie van hout uit de dakconstructie boven de tweede beuk van de voormalige Karmelietenkerk verwijst naar twee 


\section{CHARLES, R. DE HERDT, M.C. LALEMAN}

bouwfazen, respectievelijk in $1520-1530$ en na 1583 te dateren. Geillustreerd.

386. LALEMAN M.C. en P. RAVESCHOT (†), L'hôpital de la Bijloke à Gent: premier bilan de la recherche archéologique, in Actes du LIe Congrès de la Fédération des Cercles d'Archéologie et d'Histoire de Belgique, Liège, 1994, nr. 2, p. 129-135.

Overzicht van de bouwgeschiedenis van het Bijlokehospitaal op basis van het archeologisch, bouwkundig en hernieuwd historisch onderzoek onder leiding van de Dienst Stadsarcheologie in de periode 1990-1993.

387. ERAUW H., Typische wijk in Gent. Ekkergem, in Toerisme OostVlaanderen, 43, (1994), nr. 5, p. 137-142.

388. Inventaire archéologique - Fiche $n r$. 132. De puntgevel van de refter van de Bijloke, in Ghendtsche Tydinghen, 24, (1995), nr. 1, p. 12-14.

389. KERCKHAERT N. ( $\dagger$ ), 400 Jaar Ooidonk, Gent, 1995, 142 blz. Posthuum verschenen geschiedenis van het kasteel en van de families die er hun verblijfplaats hadden, zoals de Montmorency, della Faille, du Bois de Nevele en t' Kint de Roodenbeke. Rijkelijk geillustreerd. Zie ook SERRAS H., Geschiedenis van kasteel Ooidonk. Een verre duik in het verleden, in Toerisme Oost-Vlaanderen, 44, (1995), nr. 2, p. 3-7. Summier overzicht van de geschiedenis van het ontstaan van de waterburcht.

390. KLUYSKENS P., Kapelleke Schreiboom, in Ghendtsche Tydinghen, 23, (1994), nr. 6, p. 356-364.

391. LANCLUS K., Monumenten voor de rechtspraak. Rechtbanken in OostVlaanderen, in Monumenten en Landschappen, 14, (1995), nr. 5, p. 10 28.

Behandelt onder andere het Justitiepaleis te Gent, naar een ontwerp van Louis Roelandt.

392. LAPORTE D., Architectuurgids Gent, Gent, 1994, 311 blz.

Chronologische selectie (vanaf de 10de eeuw) van openbare burgerlijke en religieuze gebouwen en van privé-gebouwen uit de woon-, amusementsen bedrijfscultuur. Met foto's, opmetingen, doorsneden en/of situatieplannen, stratenindex en lijst van bouwmeesters werkzaam te Gent. Geíllustreerd.

393. LIEVOIS D., Vroege industrie aan de Sint-Amandstraat, in Stadsarcheologie. Bodem en monument in Gent, 18 (1994), nr. 1, p. 11-21. Deze bijdrage illustreert een praktische toepassing van de z.g. nieuwe methode van huizenonderzoek voor de huizen Sint-Amandstraat 68-72 
en toont aan dat deze werkwijze ook voor panden in het voormalige SintPietersdorp bruikbaar is. Behalve over de ontwikkeling van de eigenlijke huizen en hun bijgebouwen bracht het onderzoek ook diverse gegevens aan het licht over vroege industriële bedrijvigheid in Gent. Geïllustreerd.

394. MEGANCK L., De voortuinhekken van het Miljoenenkwartier. Getuigen van een verdwijnende kunstvorm, in Stadsarcheologie. Bodem en monument in Gent, 19, (1995), nr. 1, p. 23-33.

Het inwerken van kunstige afsluitingen voor de voortuinen was een kenmerk van verscheidene stadsuitbreidingen sedert de 19de eeuw. Het z.g. Miljoenenkwartier, dat na de Wereldtentoonstelling van 1913 in de Sint-Pietersaalstwijk tot stand kwam, bewaart een zeer gevarieerde verzameling voortuinhekken die in deze bijdrage hoofdzakelijk aan de hand van de originele bouwtekeningen worden toegelicht. Geillustreerd.

395. MEGANCK L., N. POULAIN en A. DEMEY, Het Miljoenenkwartier: een Gentse woonwijk uit het Interbellum, (Kleine Kultuurgidsen Provincie Oost-Vlaanderen), Gent, 1995, 64 blz.

In de eerste hoofdstukken komen de voorgeschiedenis, de Wereldtentoonstelling van 1913 en de verkaveling van het areaal aan bod. De Interbellum-architectuur wordt er in de context van ons land en in internationaal perspectief gesitueerd. Dan komen de bouwwerken en het oeuvre van de architecten die in het Miljoenenkwartier actief waren aan de beurt. Tenslotte worden de interieurs en de voortuinhekken toegelicht. Geillustreerd.

396. MEUL V., Joseph Schadde, Academicus en historiserend bouwmeester in de tweede helft van de 19de eeuw, in Monumenten en Landschappen, 13, (1994), nr. 6, p. 8-61.

De bijdrage gaat vooral dieper in op de visie over architectuur en de betekenis van het oeuvre van de Antwerpse architect Joseph Schadde (1818-1894). Een aantal belangrijke opdrachten zoals de Handelsbeurs in Antwerpen en het station van Brugge worden uitvoeriger belicht. $\mathrm{Bij}$ het overzicht van de werken komen ook enkele Gentse gebouwen aan bod zoals de kastelen Claeys Bouüaert, van Tieghem de ten Berghe en Kervyn d'Oudt Mooreghem in Mariakerke. Geilllustreerd.

397. NYS R., Het Gravensteen in Gent. Natuursteen uit het poortgebouw, in Stadsarcheologie. Bodem en monument in Gent, 18, (1994), nr. 1, p. 2427.

Verslag van het petrografisch onderzoek van het gesteente waaruit de met bladwerk versierde kraagstenen in het poortgebouw van het Gravensteen werden vervaardigd. Geillustreerd. 


\section{CHARLES, R. DE HERDT, M.C. LALEMAN}

398. OLLIVIER H. (red.), Met licht geschreven. Foto's uit een eeuw dagelijks leven, (Bijdragen Museum van de Vlaamse Sociale Strijd, nr. 12), Gent, 1994, 271 blz.

Fotoboek van éen eeuw sociale geschiedenis te Gent rondom thema's uit het dagelijks leven: werksituatie, mobiliteit, ontspanning, consumptiegedrag, sport en toerisme.

399. POULAIN N., Het Miljoenenkwartier. Beschouwingen over monumentenzorg in een beschermd stadsgezicht, in Interbellum, 15, (1995), nr. 4, p. 8-15.

400. Roelandt briljant, (Dienst Monumentenzorg en Directie Culturele Zaken), Gent, 1995, 23 blz.

Met bijdragen van DECAVELE J., De Opera van Gent. Kouter (p. 4-15) en van ZABEAU-VAN DER VERREN L., De Aula van de Gentse Universiteit. Voldersstraat, (p. 16-23).

401. SPATZ H., Gentse parken en groenzones. Deel II. Het Benard- of Muinkpark, in G.O.V. Heraut, 30, (1995), nr. 2, p. 19-32.

402. VAN DEN BOSSCHE H., Het Metselaarshuis te Gent. Bericht van een omstreden restauratie, in Monumenten en Landschappen, 13, (1994), nr. 5, p. 8-30.

Kritische bijdrage met een verantwoording van het omstreden restauratieproject van de voorgevel van het Metselaarshuis, een middeleeuws stadshuis dat in 1526 door de metselaars werd aangepast.

403. VAN DOORNE G. (red.), Open Monumentendag Gent 10 september 1995, (Dienst Monumentenzorg), Gent, 1995, $106 \mathrm{blz}$.

Rond het thema 'Samenleving Onder Dak' werden in Gent met de Open Monumentendag een dertigtal monumenten in de belangstelling gebracht. De klemtoon lag op burgerlijke openbare gebouwen of sites met een publieke functie zoals begraafplaatsen. Daarnaast werden ook enkele kleinere en minder bekende museumverzamelingen voorgesteld. In de Sint-Pietersaalstwijk waar in de Interbellumperiode het z.g. Miljoenenkwartier ontstond, werden enkele woningen uitgekozen om meer in detail aan het publiek voor te stellen. Aan de brochure waarin elke lokatie bondig wordt toegelicht, verleenden verschillende auteurs hun medewerking. Men vindt er onder meer inlichtingen over het Museum Energeia en het tuindorp Herryville (Langerbruggekaai), de Westerbegraafplaats (Palinghuizen), het neogotische Campo Santo (Mariakerke), het Psychiatrisch Centrum Dr. Guislain (Jozef Guislainstraat), de begraafplaats Campo Santo op de Kapelleberg (Sint-Amandsberg), het Museum SintJan-de Deo (Fratersplein), de voormalige Berg van Barmhartigheid of het Stadsarchief (Abrahamstraat), het Toreken (Vrijdagmarkt), het 
Gouverneurshuis (Vlasmarkt), de Koninklijke Vlaamse Academie (Koningstraat), het Historisch Archief- en Documentatiecentrum (Klein Raamhof), het Museum van de Souvereine Gilde van Sint-Joris (Buitenhof), het Stadhuis (Botermarkt), het Postgebouw (Korenmarkt), de Rijksgevangenis (Nieuwewandeling), de Koninklijke Nederlandse Schouwburg (Sint-Baafsplein), het Zwembad Van Eyck (Jules de Vigneplein), het Pand of het voormalige Domincanenklooster met de diverse erin ondergebrachte museumcollecties (Onderbergen), de Hogere Instituten Sint-Lucas (Zwartezustersstraat), het Provinciehuis (Gouvernementstraat), het Gerechtshof(Koophandelsplein), het Kunstencentrum Vooruit (Sint-Pietersnieuwstraat), de historische onderwijscollectie Universiteit Gent (Apotheekstraat), de Universiteitsbibliotheek (Rozier), de archeologische en de ethnografische verzamelingen van de Universiteit Gent (Blandijnberg/Sint-Hubertusstraat), het Museum van de Sint-Rochusgilde (Sint-Pietersplein), het Sint-Pietersinstituut Gent (Meersstraat), het Museum voor Dierkunde (Lodewijk Ledeganckstraat), woonhuis Storrer en het huis Spitaels (Onafhankelijkheidslaan), de woning De Bondt (Krijgslaan), de woning Sarteel (Vaderlandstraat), de parochiekerk Sint-Pieters-Buiten en de woning Elegeert (SintPietersaalststraat), het Museum voor de Geschiedenis van de Wetenschappen Universiteit Gent (Krijgslaan) en het Museum voor de geschiedenis van de farmacie (Harelbekestraat). Geilllustreerd.

404. VAN NEVELE F., Van Dampoortbrug tot Sint-Jorisbrug, (Koninklijke Dekenij Nieuwenhove), Gent, 1995, z. blz.

405. VERBEKE A., Het volksblazoen van Gent, in Ghendtsche Tydinghen, 24, (1995), nr. 4, p. 220-222.

Bespreking van een glasraam in het Gentse stadhuis, voorstellende "het Volksblazoen van Gent".

406. VERMEIRE M., Gentse parken en groenzones. Domein en wandelpark Slotendries gemeente Oostakker, in G.O.V. Heraut, 30, 1995, nr. 3, p. 3344.

407. VERVAET A., Het kasteel van Lochristi, in De Oost-Oudburg. Jaarboek, XXXI, (1994), p. 5-17.

Geschiedenis van het kasteel Rozelaar te Lochristi, ooit het buitenverblijf van de abt van Sint-Baafs en van de Gentse bisschoppen (vanaf eind 16de eeuw); hertekend door Louis Minard in 1833 in neoclassicistische stijl en sedert 1859 vaste stek van de bloemistenfamilie Vuylsteke. Geïllustreerd.

408. VER VAET B., Het 'Kasteel van Saffelaere" naar een ontwerp van Jan Rooms, in Heemkundig Nieuws, 23, (1995), nr. 2, p.8-9. 


\section{CHARLES, R. DE HERDT, M.C. LALEMAN}

409. Vijfde dag van het park, 28 mei 1995: Maaltebruggepark. Het park, poort tot de natuur, (Plantsoenendienst), Gent, 1995, 6 blz., 4 blz., 6 blz., 10 blz.

Historiek van het domein Claeys-Bouüaert (Mariakerke), het Frans Tochpark - Voordries - Rattendale (Gentbrugge) en het Citadelpark (Gent) en met bespreking van het Maaltebruggepark. Met plannen van de wandelroutes.

410. WORTMANN A., Een plek in een dorp, woning in Mariakerke van Xaveer de Geyter, in Archis, 1995, nr. 3, p. $42-47$.

Voorstelling van een merkwaardig woonhuis in eigentijdse architectuur, gelegen in een recente verkaveling te Mariakerke.

Kunst, Cultuur

411. BLUEBAUM D., Die Behandlung der Kunst der Alten in der Zeitschrift $>$ Onze Kunst<. Kunstgeschichte im Spannungsfeld von Sprache und Politik in Belgien, (Berichte aus der Literaturwissenschaft), Aachen, 1994, 221 blz.

Studie van het te Antwerpen uitgegeven kunsttijdschrift "Onze Kunst" (1902-1929), dat ook in Nederland verspreiding vond, en waaraan onder meer werd meegewerkt door de Gentse kunstenaar Charles Daudelet (1861-1938). Tevens worden de erin verschenen bijdragen behandeld over de Latemse school en over de tentoonstelling "Oude Kunst in Vlaanderen" op de Wereldtentoonstelling van Gent in 1913.

412. BRINKMAN P., Het geheim van Van Eyck. Aantekeningen bij de uitvinding van het olieverven, Zwolle, 1994, $347 \mathrm{blz}$.

Technische studie over het gebruik van de olieverftechniek, met uitgebreide analyse van de materialen en de technieken aangewend bij het "Lam Gods". Geillustreerd, met kritisch apparaat.

413. DECAVELE J. (red.), Hugo Claus 65, (Stadsarchief, Museum Arnold Vander Haeghen en Poëziecentrum), Gent, 1994, 125 blz.

Publikatie naar aanleiding van de 65 ste verjaardag van Claus waarin diverse aspecten van diens literaire oeuvre worden belicht. Met bijdragen van H. CLAUS, Te Gent (p. 7-12), J. VAN GOOL, Biografische schets (p. 15-31), D. DE GEEST, Poëzie (p. 33-56), F. DE VREE, Proza (p. 5768), J. VAN SCHOOR, Theater (p. 69-78), F. DECREUS, Mythen uit de Oudheid (p. 79-95), F. HEYMANS, Hugo Claus inden de prijzen (p. 97104) en G. J. HEMMINK, Bibliografie (p. 105-124). Geillustreerd.

414. DEN HARTOG E., Het mecenaat van Filips van de Elzas en zijn opvolgers. Over de oorsprong van het Ingeborgpsalter en de verbreiding van de 'Muldenstil', in Handelingen van de Maatschappij voor Geschie- 


\section{BIBLIOGRAFIE VAN DE GESCHIEDENIS VAN GENT 1994-1995}

denis en Oudheidkunde te Gent, XLVIII, (1994) p. 1-102.

De auteur gaat dieper in op enkele aspecten van de kunstproduktie in Vlaanderen in de late 12 de eeuw en verbindt dit met de hofcultuur ten tijde van graaf Filips van de Elzas. Twee verluchte handschriften, met name het z.g. Ingeborgpsalter en een psaltercommentaar uit de Pierpont Morgan-verzameling vormen de kern van deze grondige studie. Bij de verspreiding van de z.g. Muldenstil die met deze kunstwerken wordt geassocieerd, betrekt de auteur ook de sculpturen uit het westportaal van de Sint-Niklaaskerk met verscheidene voorstellingen uit het passieverhaal. Hierbij wordt een nieuwe hypothese voorgesteld, waarvoor diverse argumenten ter ondersteuning worden aangehaald. De sculpturen zouden afkomstig zijn van een koorafscheiding of doksaal en zouden omstreeks 1206 vervaardigd zijn. Ze zouden voor de Sint-Veerlekerk gemaakt zijn en in 1598-1599 of kort daarvoor, parallel aan de verhuis van het kanunnikenkapittel, naar de Sint-Niklaaskerk overgebracht zijn en toen in een nieuwe, typologische compositie in het tympaan van het westportaal verwerkt zijn. Geilllustreerd.

415. DE PATOUL B. en R. VAN SCHOUTE (red.), Les Primitifs flamands et leur temps, (La Renaissance du Livre), Louvain-la-Neuve, 1994, 656 blz. Voor Gent zijn zeker van belang de bijdragen over Hubert en Jan van Eyck (C. STROO en M. SMEYERS, p. 287-309) en over Hugo van der Goes (P. EECKHOUT, p. 415-435). Interessant is ook de behandeling van de minder beroemde meesters op het einde van de 15de eeuw te Gent (P. EECKHOUT, p. 516-523) waarin onder meer het werk van Gerard Horenbaut wordt besproken. Rijk geilllustreerd.

416. DEPREZ A. (red.), Karel van de Woestijne. Verzameld journalistiek werk. Deel XV, (Cultureel Documentatiecentrum), Gent, 1995, 618 blz.

417. DE VOS J., Het toneelleven in Gent 1992-1993, in Kultureel Jaarboek voor de Provincie Oost-Vlaanderen, 47, (1993), p. 83-91.

418. D'HOLLANDER J., Gentse kamerbeiaard Van den Gheyn uit 1801 gerestaureerd, in G.O.V.Heraut, 30, (1995), nr. 2, 4 blz.

419. GINSBURGH V. en S. MERTENS, De moderne en hedendaagse Belgische schilderkunst. Evolutie van de prijzen in de internationale verkopen 1962-1992, in Het Tijdschrift van het Gemeentekrediet, XLVIII, (1994), nr. 190, p. 57-79.

In de bijdrage gaat het over een methodologische statistiek die gegevens levert voor een waardebepaling van kunstwerken en wordt de zienswijze getoetst aan concrete voorbeelden van de moderne en hedendaagse schilderkunst. Heel wat Oostvlaamse en Gentse kunstenaars, of schilders van wie werk in Gentse musea voorkomt, komen in dit artikel aan bod. 


\section{CHARLES, R. DE HERDT, M.C. LALEMAN}

420. HUYS P., Een klein zenuwachtig stadje, in Ghendtsche Tydinghen, 24, (1995), nr. 4, p. 200-206.

Bespreking van de ets "Une petite ville un peu nerveuse" (1925-26) van Jules De Bruycker. Zie ook ID., Ik zou een tekening willen maken ... in Ghendtsche Tydinghen, 24, (1995), nr. 3, p. 152-159. Over een tekening (1913) van de Onthoofdingsbrug en ID., "Les Journalistes", een ets van Jules De Bruycker (1907), in Ghendtsche Tydinghen, 24, (1995), nr. 2, p. 51-63. Identificatie van de personages: de journalisten Albert De Moor (Le Bien Public), Filiep De Munnynck (Het Volk) en Gustave Abel (La Flandre Libérale), de advocaat Gustave Eylenbosch en stadssecretaris Aimé De Bruycker.

421. Inventaire archéologique - Fiche $n r$. 10. Beeldhouwwerk van Norbert Sauvage in het Bureel van Liefdadigheid, in Ghendtsche Tydinghen, 24, (1995), nr. 2, p. 64-66.

422. Inventaire archéologique - Fiche $n$ r. 59. Boekband van het register van de Brouwersnering, in Ghendtsche Tydinghen, 23, (1994), nr. 6, p.355356.

423. Inventaire archéologique - Fiche $n r$. 2. Het leven van Sint-Amandus, in Ghendtsche Tydinghen, 24, (1995), nr. 4, p. 199.

424. Inventaire archéologique - Fiche nr. 28. De Stichting Bernard Rubeys, in Ghendtsche Tydinghen, 24, (1995), nr. 3, p. 133-134.

Bespreking van de gedenksteen in de Kapel van de Schepenen en de inhoud van de stichting gedaan door koopman Bernard Rubeys in 1574.

425. LAMARCQ D., Geschiedenis in hardsteen en brons. "Historische" standbeelden in Oost-Vlaanderen, in Toerisme Oost-Vlaanderen, 44, (1995), nr. 3, p. 48-54.

Met vermelding van diverse Gentse standbeelden van onder andere Jacob van Artevelde, Lieven Bauwens, Louis van Houtte, Oswald de Kerchove de Denterghem en Emile Braun.

426. Museum voor Geschiedenis der Geneeskunde. Gids, (Stichting Jan Palfyn), Gent, 1995, 63 blz.

Rijk geîllustreerde catalogus van het Museum dat onder impuls van de Stichting Jan Palfyn sedert 1991 een onderkomen vond in de middenvleugel van het gerestaureerde 13de eeuwse Dominikanenklooster "Het Pand" aan de Leie. Met aandacht voor de paleopathologie en met een overzicht van het geneeskundig instrumentarium.

427. NYS L., A propos d'une concession de sépulture à perpétuité en l'église Saint-Nicolas-en-la-Couture de Valenciennes (1377, n.st.). Ladisparition 


\section{BIBLIOGRAFIE VAN DE GESCHIEDENIS VAN GENT 1994-1995}

des dalles à effigies dans les églises: une certaine conception de la concession à perpétuité, in Revue des archéologues et historiens d'art de Louvain, XXVI, (1993), p. 171-173.

De auteur vestigt er de aandacht op dat de kerkverantwoordelijken geregeld een opruiming hielden in de gegraveerde of gebeeldhouwde grafplaten en de monumentale epitafen. Hoewel de familie betaald had voor een eeuwigdurende concessie, hield men later weinig rekening met de contracten, geschreven of niet, die bij deze gelegenheid gesloten waren. De voornaamste beeldstormers en verwoesters van grafmonumenten waren uiteindelijk deze kerkverantwoordelijken. De auteur verwijst nadrukkelijk naar gevallen waar grafplaten voor profane doeleinden herbruikt werden, onder meer bij de aanleg van de Braamgatensluis in Gent.

428. SCHMIDT P., Het Lam Gods, Leuven, 1995, 79 blz.

Rijk geillustreerde interpretatie van het iconografisch programma van het beroemde veelluik.

429. STEVENS M. en R. HOOZEE (red.), Impressionisme en Symbolisme. De Belgische avant-garde 1880-1900, (Royal Academy of Arts), London, 1994, 295 blz.

Catalogus van de gelijknamige tentoonstelling. Het werk van Belgische en Gentse kunstenaars wordt belicht: Emile Claus, Henri De Braekeleer, James Ensor, Fernand Khnopff, Constantin Meunier, George Minne, Félicien Rops, Léon Spilliaert, Henry Van de Velde, Théo Van Rysselberghe en Theodoor Verstraete. Geîllustreerd.

430. T'SJOEN Y. en H. VANDEVOORDE, Op voet van gelijkheid. Opstellen van Anne Marie Musschoot, (Studia Germanica Gandensia, nr. 36), Gent, 1994, 251 blz.

Bundeling van opstellen met onder meer haar belangrijkste bijdragen over Karel van de Woestijne en Cyriel Buysse.

431. Toneelvereniging G.B. Shaw vzw. Gent 1944-1994-50 jaar, Gent, 1994, $78 \mathrm{blz}$.

432. VAN CLEVEN J. en F. VAN TYGHEM (red.), Neogotiek in België, Gent, 1994, 223 blz.

Rijk geillustreerd werk, met onder meer opstellen van L. FRANCOIS, De neogotiek in België: de historische context (p. 22-25), J. VAN CLEVEN, Meester Jean-Baptiste Béthune (1821-1894): een kunstenaarsloopbaan (p. 168-199) en T. COOSMANS, Architect Pierre Langerock (18591923) (p. 152-153). 


\section{CHARLES, R. DE HERDT, M.C. LALEMAN}

433. VAN ELSLANDER A. en A.M. MUSSCHOOT (ed.), Correspondentie van de gezusters Loveling. Brieven van en naar Paul Fredericq II, in Mededelingen van het Cyriel Buysse Genootschap, X, (1994), p. 31-156. Tweede deel van de publikatie van deze briefwisseling (zie Mededelingen ..., IX, (1993), p. 67-175).

434. VAN PETEGHEM S. (red.), Johan Daisne: 10 films 10 bioscopen, (Universiteitsbibliotheek en Internationaal Filmfestival van Vlaanderen), Gent, 1994, 88 blz.

Filmretrospectieve van tien favoriete films van deze auteur van het magisch realisme, met catalogus van de tentoonstelling van documenten uit het filmarchief van Johan Daisne in de Gentse Universiteitsbibliotheek.

435. Van Tent naar Teater. 20 jaar Gents Amusement Teater, Gent, 1995, $71 \mathrm{blz}$.

436. VERKERKEN W., Het land van Buysse, volgens Cyriel Buysse. Een inventaris van de realiteit en het fantasierijke realisme in de topografie van het oeuvre van Cyriel Buysse, (Cyriel Buysse Genootschap), Gent, 1994, 207 blz.

Hoe verwerkte Buysse zijn omgeving in zijn literair werk ? Voor Gent is deze omgeving onder meer: de Bijloke, de Kouter, de Vismarkt, het station en de beestenmarkt.

437. VIANE R., Bloemen, Planten en Platen. 18de eeuw tot heden, (Universitaire Plantentuin), Gent, 1995, 83 blz.

Catalogus bij de tentoonstelling die de eerste planten- en bloemententoonstelling in de herberg Frascati (1809) reconstrueert, waaruit later de Gentse Floraliën zijn ontstaan.

Materiële cultuur

438. DE BACKER C., Een Gents recept uit de 16de eeuw om "tragien" te maken, in Scientiarum Historia, 20, (1994), nr. 1-2, p. 71-74.

Tragien zijn suikerwerken dragees. Met kritisch apparaat.

439. DE BACKER C., Het vernis-recept uit 1756 voor de bibliotheek van de Sint-Pietersabdij te Gent, in Stadsarcheologie. Bodem en monument in Gent, 18, (1994), nr. 1, p. 22-23.

In het Museum voor Volkskunde bevindt zich een handschrift met 18deeeuwse vernisrecepten van een zekere Pieter Bettens die wellicht als schilder-decorateur werkzaam was. Een recept voor vernisactiviteiten in de bibliotheek van de Sint-Pietersabdij wordt hier in extenso gepubliceerd en van commentaar voorzien. 
440. DEMIDDELE H. en A. ERVYNCK, Diatomeeën als ecologische indicatoren in de Vlaamse archeologie: Romeins en middeleeuws Oudenburg (prov. West-Vlaanderen), in Archeologie in Vlaanderen, AsseZellik, 1993, dl. 3, p. 271-231.

Kiezelwieren of diatomeeën bieden waardevolle aanwijzingen voor de reconstructie van het landschap en de vegetatie rond archeologische contexten. Kiezelwieren bezitten immers een vrij resistent skelet en hebben daarom grote fossilisatiekansen. Ze komen bovendien in bijna alle aquatische biotopen in grote aantallen voor. De kans dat in een archeologische context grote hoeveelheden kiezelschaaltjes voorkomen, is reeël. Het onderzoek van dit soort ecologisch bodemmateriaal wordt in Vlaanderen nog te weinig toegepast. Met verwijzing naar de onderzoeken van de Hogeweg en de wellicht 9de-eeuwse grachtvulling aan de Gouvernementstraat. Geïllustreerd.

441. LAMARCQ D., Het latrinaire gebeuren. De geschiedenis van het W.C., (Stichting Mens en Kultuur), Gent, 1993, 308 blz.

Zeer ruim en algemeen overzicht van de geschiedenis van de latrine, met enkele verwijzingen naar Gent. Zo werden de structuur en het functioneren van de nog bewaarde latrines in het Gravensteen en het Korenstapelhuis aan de Graslei toegelicht. Er komen verwijzingen voor naar enkele privé-woningen, onder meer in de Drabstraat en de Heilig-Geeststraat. Het archeologisch onderzoek van een post-middeleeuwse beerput aan de Schepenhuisstraat en vondstengoed uit een afvalput die in de infirmerie van de Sint-Pietersabdij werd opgegraven, kregen eveneens een plaats in dit werk. Bij de Gentse verwijzingen ontbreekt ook de latrine niet, horend bij de troon van Jozef II en bewaard in de Troonzaal van het Gentse Stadhuis.

Voor de meer recente periodes komen stedelijke voorschriften aan bod, situaties in Gentse beluiken, documenten uit het Museum voor Volkskunde en gegevens over urinoirproduktie zoals wat door het huis DutryColson werd verdeeld. Geillustreerd.

442. VAN DEN ABEELE R., Bakstenen en veldsteenovens langs de Leie te Sint-Martens-Latem en omgeving, in Heemkring Scheldeveld. Jaarboek, (1994), nr. 23, p. 99-119. Geíllustreerd.

De bijdrage handelt over het functioneren van veldovens waarin bakstenen werden vervaardigd. Het gaat om een beknopt overzicht voor SintMartens-Latem met gegevens vanaf de 16de eeuw. Een klein gedeelte van de produktie werd geëxporteerd, wellicht naar Gent en de Gentse deelgemeenten. De meeste aandacht van de auteur gaat uit naar de manier waarop de laatste veldovens in de Interbellumtijd werden opgebouwd en wie daarbij betrokken was. Dit thema biedt tevens de gelegenheid om voor die periode ook informatie te geven over de vervaardiging van baksteen in Afsnee en Sint-Denijs-Westrem. 


\section{CHARLES, R. DE HERDT, M.C. LALEMAN}

Heemkunde, volkskunde, genealogie

443. AUDOOREN F. (red.), Het vuur aan de lont ... biografie van 25 jaar Gentse Feesten bij Sint-Jacobs, (vzw Trefpunt), Gent, 1994, 232 blz. Geillustreerd.

444. BAILLIEUL B., In hoeverre is het archief van de Gentse schuttersgilden genealogisch waardevol ?, in VVF-Informatieblad Afdeling Gent, XIV, (1995), nr. 1, p. 10-13.

445. BOERJAN G., Het kerkhof van Mariakerke "anders bekeken" deel 2, in Marka. Notulenblad, 111, (1994), z. blz.

Voorstelling van de merkwaardige graven op het kerkhof en van de kunstenaars die eraan werkten. Geilllustreerd.

446. BONTINCK J. en P. NOLLET, Meulestede nu - 1994 ten behoeve van de huidige en de komende generaties, (Stad Gent), Gent , 1994, 38 blz.

Fotobrochure over het hedendaagse straatbeeld in de wijk Meulestede.

447. BROGET G., "De groete strate buten turre", in Ghendtsche Tydinghen, 24, (1995), nr. 3, p. 114-133; nr. 4, p. 182-198.

Beschrijving en historiek van de voornaamste panden langsheen de Hoogstraat. Geïllustreerd.

448. BRYSSE A., Typische wijk in Gent. De Muide, in Toerisme OostVlaanderen, 43, (1994), nr. 4, p. 103-107.

449. DAEM M., Het Heilig Bloedkapelleke Ekkergem-Gent en Wilsnack (D), in Oostvlaamse Zanten, LXIX, (1994), nr. 3, p. 141-175.

450. DAEM M. en M.J. DE SMET, Kinderlied, -dans en -spel te Wetteren, in Oostvlaamse Zanten, LXIX, (1994), nr. 4, p. 203-237.

451. DE BAETS A., De slag van Melle $a^{\circ}$ 1745. De gevolgen voor de inwoners, in Heemkundige Vereniging De Gonde, 23, (1995), nr. 2, p. 3541.

452. DE BUCK R., Herontdekking van de Nieuwpoort, in Ghendtsche Tydinghen, 24, (1995), nr. 2, p. 97-100.

Met reproductie van een foto van de Nieuwpoort in 1853.

453. DE BUCK R. (ed.), Gentse memoriedagen, in Ghendtsche Tydinghen, 23, (1994), nr. 5, p. 314-316; nr. 6, p. 368-371; 24, (1995), nr. 1, p. 32; nr. 2, p. 100-102; nr. 3, p. 160-163, nr. 4, p. 230-232. 
454. DE CLERCQ R., De inwoners van Sint-Denijs-Westrem in de commerciële repertoria van de 19de eeuw, in Heemkring Scheldeveld. Jaarboek, XXIII, (1994), p. 43-97.

Systematisch overzicht van de bevolking volgens verschillende beroepscategorieën, met bronvermeldingen. Geillustreerd.

455. De geschiedenis der lotelingen, in Marka. Notulenblad, (1995), nr. 112, nr. 113.

Met chronologisch overzicht van de lotelingen van Mariakerke (17941899).

456. DEGRAEUWEG.(red.),Dorpsbeelden uithet verleden. Melle-Gontrode, Nazareth, 1994, 126 blz.

Fotoboek met afbeeldingen van sociale bijeenkomsten (toneel, muziek, school ...) en met dorpszichten van Melle en Gontrode.

457. DE MAAR F., De heilige Apollonia in Nederland en Vlaanderen. Duizend jaar beschermheilige van de tandpijnlijders en in de twintigste eeuw van de tandartsen, Nijmegen, 1991, 56 blz.

Studie van de verering van deze heilige, met aandacht voor de $15 \mathrm{de}-$ eeuwse muurschildering in de crypte van de Sint-Baafskathedraal. Geîllustreerd.

458. DENEWET L. en L. GOEMINNE, Molenmakers in Vlaanderen. Het werkboek van Coussée uit Meulebeke (1881-1911), in Molenecho's, 22, (1994), nr. 3-4, p. 108-333.

459. DESMET J. en C. DETREMMERIE (e.a.), Koninklijke Gentse Kapperskring 1893-1993, Gent, 1993, 112 blz.

Historiek van techniek en mode in het kappersberoep. Geilllustreerd.

460. DE TREMERIE M., Herbergnamen. Spiegel van hun tijd, in Toerisme Oost-Vlaanderen, 44, (1995), nr. 3, p. 61-63.

461. DE VRIENDT J. ( $\dagger$ ), Afstammelingen Beenhouwers en Visverkopers VANLOO uit Gent. Nakomelingen van de kinderen van Carel-Dominicus van Loo x De Munnynck Martina-Joanna, in VVF-Informatieblad Afdeling Gent, XIV, (1995), nr. 1, p. 6-7.

462. EVRARD A. en R. DE VRIENDT-MORES, Suïcide (en moord) onder het Ancien-Régime. Een criminele saeck in het milieu van de Gentse vleeshouwersnering, in Ghendtsche Tydinghen, 24, (1995), nr. 1, p. 1522.

De moord door en zelfmoord van de vleeshouwer Frans van Loo in 1741 geeft een kijk op de de rechtspraak en de aanpak van psychiatrische 


\section{CHARLES, R. DE HERDT, M.C. LALEMAN}

patiënten in de 18 de eeuw te Gent.

463. HAUDENHUYSE G., Misdaad en straf in de middeleeuwen, niet steeds evenredig, in Driemaandelijks Tijdschrift Heemkundig Genootschap Land van Rode, 23, (1995), nr. 2, p. 17-22.

464. HAUDENHUYSE G., Opsporingsbericht uit 1330, in Driemaandelijks Tijdschrift Heemkundig Genootschap Land van Rode, 23, (1995), nr. 2, p. 23-26.

465. LAMARCQ D., Ook in Oost-Vlaanderen spiegels van de samenleving: Herbergnamen, in Toerisme Oost-Vlaanderen, 44, (1995), nr. 1, p. 1922.

466. LEVIS E., 't Gentsch spant de Kruune of: het fenomeen van het fabrieksgents, in Tijdschrift voor Industriële Cultuur, 12, (1994), nr. 4, p. 3-23.

467. LEVIS E. en G. VAN GEERT ( $\dagger)$, Kaak, kaak, nen twiedekker! Gensche woorde en uitdrukkynge, in Ghendtsche Tydinghen, 23, (1994), nr. 6, p. 373-376; 24 (1995), nr. 1, p. 35-38; nr. 2, p. 103-106; nr. 3, p.164-167.

468. MAES D., Wie was ereerst: de leenheer of de leenman? De Heerlijkheid Drongen en haar lenen, in Dronghine. Jaarboek, (1995), p. 95-152.

469. Mariakerke \& Mariakerkenaars tijdens wereldoorlog II, in Heemkundige Kring Marka, 1994, z. blz.

470. MATTELAER J.J., Steensnijden in Vlaanderen in de 17de en 18de eeuw, in Geschiedenis der Geneeskunde, (1995), nr. 1, p. 57-65.

Bijdrage over deze vroege "heelkundige" ingreep. Met aandacht voor de Gentse familie steensnijders De Pape.

471. NEIRYNCK F. en H. PAERL, Traditionele poppen in België, (Vlaams Figurenteaterarchief), Gent, 1994 , z. blz.

Behandelt de plaats van het Belgisch traditioneel poppentheater in Europa en de diverse Belgische gezelschappen (met Pierke voor Gent). Geillustreerd.

472. OSSIEUR E., Het doopfeest van Albert van Pottelsberghes zevende zoon in 1696, in Ghendtsche Tydinghen, 24, (1995), nr. 2, p. 72-83.

Bevat tevens gegevens over de aanverwante familie Schoorman..

473. POELMAN R., De schuttersmaatschappij Willem Tell aan de Oude Bareel, in De Oost-Oudburg. Jaarboek, XXXI, (1994), p. 125-133. 


\section{BIBLIOGRAFIE VAN DE GESCHIEDENIS VAN GENT 1994-1995}

474. POELMAN R., Het verhaal van een grafzerk, in Heemkundig Nieuws, 23, (1995), nr. 1, p. 2-3.

De grafsteen van Daniël Kutschrütter, vroegere bewoner van het domein Slotendries en begraven (1720) in de parochiekerk van Oostakker, werd eind 19de eeuw door Nederlandse afstammelingen gekocht en naar Den Haag overgebracht. Is nu terug geplaatst in de gang van het Convent Engelbertus in Sint-Amandsberg.

475. SCHEPENS E., Wie heeft het voor het zeggen? Twee processen met betrekking tot de jurisdictie van de heerlijkheid Baarlevelde (te Drongen), in Dronghine. Jaarboek, (1995), p. 37-73.

476. SELIS E., Oostakkerse kronieken, Oostakker, 1994, 96 blz.

Verzameling van dorpsverhalen. Geillustreerd.

477. SONNEVILLE A., Zwijnaarde eertijds en nu, deel 2, Zwijnaarde, 1995, $96 \mathrm{blz}$.

Fotoboek over het leven in een dorpsgemeenschap met veel aandacht voor het landbouwersbestaan.

478. STEEGHERS W., 15de eeuwse Gentse buitenpoorters uit Brugge, in Vlaamse Stam, 31, (1995), nr. 3-4, p. 206; zie ook ID., 15de-eeuwse Gentse Buitenpoorters uit Ertvelde, in Appeltjes van het Meetjesland. Jaarboek, (1995), nr. 45, p. 105-106; ID., 15de eeuwse Gentse buitenpoorters uit Sint-Niklaas, in Vlaamse Stam, 31, (1995), nr. 2, p. 7980; ID., Asperlingen die Gents buitenpoorter werden in de 15de eeuw, in Vlaamse Stam, 30, (1994), nr. 11-12, p. 559-560; ID., Drongenaren die Gents Buitenpoorter werden in de 15de eeuw, in Dronghine. Jaarboek, (1995), p. 25-28; ID., Gentse buitenpoorters van Destelbergen in de 15 de eeuw, in Heemkundig Nieuws, 23, (1995), nr. 1, p. 13-14; ID., Gentse buitenpoorters van Gentbrugge in de 15de eeuw. Gentse buitenpoorters van Ledeberg in de 15de eeuw, in Vlaamse Stam, 30 (1994), nr. 11-12, p. 606; ID., Gentse buitenpoorters van Heusden (Oost-Vlaanderen) in de 15de eeuw, in Vlaamse Stam, 31, (1995), nr. 6, p. 320-322; Gentse buitenpoorters van Merelbeke in de 15de eeuw, in Vlaamse Stam, 31, (1995), nr. 1, p. 31-32; ID., Gentse buitenpoorters van Oostakker en SintAmandsberg in de 15de eeuw, in Heemkundig Nieuws, 22, (1994), nr. 3, p. 15; ID., Gentse buitenpoorters van Wetteren in de 15 de eeuw, in Vlaamse Stam, 31, (1995), nr. 7-8, p. 371-374; ID., Kaprijkenaren die Gents buitenpoorterwerden in de 15de eeuw, in De Eik, 19, (1994), nr. 4, p. 207-208; ID., Lovendegemnaren die Gents buitenpoorter werden in de 15de eeuw, in De Eik, 20, (1995), nr. 1, p. 5-6; ID., Personen uit Aalst die Gents buitenpoorter werden in de 15de eeuw, in Vlaamse Stam, 30, (1994), nr. 9, p. 455-457; ID., Sleidingenaren die Gents buitenpoorter werden in de 15de eeuw, in De Eik, 20, (1995), nr. 1, p. 3-5; ID., 


\section{CHARLES, R. DE HERDT, M.C. LALEMAN}

Zingemnaren die Gents buitenpoorter werden in de 15de eeuw, in Vlaamse Stam, 30, (1994), nr. 10, p. 515-516.

479. STEEGHERS W., Genealogische gegevens betreffende de familie van de geneesheer en letterkundige Judocus Frans De Hoon, in De Eik, 20, (1995), nr. 1, p. 44-47.

480. STEEGHERS W., Personen uit het Meetjesland overleden op de parochie Sint-Michiels-Noord te Gent (1736-1796), in Appeltjes van het Meetjesland. Jaarboek, (1995), nr. 45, p. 107.

481. STOCKMAN L., De H.-Kruisdevotie in Lotenhulle voor 1796, in Appeltjes van het Meetjesland. Jaarboek, 45, (1994), p. 167-180.

482. TIMMERMAN F., Dorpsbeelden uit het verleden. Merelbeke. Deel 2, Nazareth, 1994, 126 blz.

Fotoboek met aandacht voor het dagelijks leven en het verenigingsleven.

483. VAN DE PERRE D., Het toponiem "Kardeloet" te Ninove en te Gent en zijn relatie tot de Middeleeuwse Arturromans, in Het Land van Aalst, XLVII, (1995), nr. 1, p. 64-76.

Het huis Cardeloot (1321) was een steen in de Hoogpoort, gelegen ongeveer waar het huidige laat-gotische Stadhuis is gebouwd.

484. VAN DER LINDEN R., Heemkringen in Zuid-Oost-Vlaanderen, in Toerisme Oost-Vlaanderen, 43, (1994), nr. 5, p. 118-121.

485. VAN DE WALLE R., Toverij in Vlaanderen, in DE MEUTER I. en M. PORIAU (red.), Witte magie, zwarte magie, Brussel, 1995, p. 76-101. Behandelt de toverij in Vlaanderen (tot in de 20ste eeuw), met aandacht voor enkele typisch Gentse verschijnselen.

486. VAN GANSBEKE J., Drongense kermiskoersen tussen 1930 en 1980, in Dronghine. Jaarboek, (1995), p. 9-24.

Historisch overzicht geïllustreerd met krantenknipsels en foto's.

487. VAN POUCKE D., Royal Cody Ghent Rifle Club 1895-1995, Gent, 1995, 175 blz. Geïllustreerd.

488. VAN TWEMBEKE J., 25 Jaar Heemkring Scheldeveld, in Heemkring Scheldeveld. Jaarboek, (1994), nr. 23, p. 155-181. Geillustreerd.

Het werkgebied van deze vereniging, die in 1969 werd opgericht, omvat ook de deelgemeenten Afsnee, Sint-Denijs-Westrem en Zwijnaarde. Zowel in de werking als in de publikaties komen vaak onderwerpen aan bod die ook deelaspecten van het Gentse verleden aansnijden. 
489. VELLE K., Hongeropstand in Sint-Martens-Latem in 1847, in Heemkring Scheldeveld. Jaarboek, XXIII, (1994), p. 7-23.

490. VELLE K., "Scheiden doet lijden": de boedelscheiding tussen de gemeenten Nazareth en De Pinte (1867-1871), in Heemkring Scheldeveld. Jaarboek, XXIII, (1994), p. 25-39.

\section{Biografieën}

491. In memoriam, in Kultureel Jaarboek voor de Provincie Oost-Vlaanderen, 47, (1993), p. 275-286.

Gentenaars overleden in 1993: direkteur van de Federatie voor Toerisme in Oost-Vlaanderen Daniel De Moor (Gent, 1932), de kunstenaars: Oscar Bonnevalle (Gent, 1920), Herman Verbaere (Wetteren, 1905), Gustaaf Charles Verhasselt (Gent, 1902), Roger Bracke (Lokeren, 1913), Roland Monteyne (Lauwe, 1932); Robert De Smet (Gent, 1937), artistiek raadgever van de Kommissaris-Generaal van Europalia 93 Mexico, de literair criticus Remi Van De Moorter (Petegem aan de Leie, 1912), dichter Frank Meyland (Gent, 1920), priester Jozef De Wilde (Sint-Amandsberg, 1906), tevens bestuurslid van de Oudheidkundige Kring van het Land van Waas, musicoloog Jozef Robijns (Meldert, 1920) en akteur-regisseur Dries Wieme (Gent, 1927). Met foto's van de overledenen.

492. Nouvelle Biographie Nationale, 3 (Académie Royale des sciences, des lettres et des beaux-arts de Belgique), Brussel, 1994, 376 blz.

Betreffende Gent zijn opgenomen: goudsmid en Brugs muntmeester Marc Ackart, Gent 1484-na 1536 (p. 11-13), kunstenaar Paul De Vigne, Gent 1843-Schaarbeek 1901 (p. 143-146), architect Langerock Pierre, Gent 1859-Leuven 1923 (p. 216-218), journalist en literator Pierre Maes, Gent 1887-Oostende 1968 (p. 243-245), professor en schrijver Albert Muller, Gent 1880-Antwerpen 1951 (p. 268-270), journalist Paul-Gustave Van Hecke, Gent 1887-Elsene 1967 (p. 331-334), politicus en topfunctionaris Eugène-François van Hoobrouck de Mooreghem, Gent 1756-Wortegem 1843 (p. 335-337).

493. CAMBIER G., Robert Aerens, een ingetogen schilder, in Heemkring Scheldeveld. Jaarboek, XXIII, (1994), p. 141-153.

Gents kunstschilder (1883-1969) te situeren in het entourage van Karel Van de Woestijne en Van den Berghe.

494. DESEYN G., Eedse Ansiele: kind van de gebuurte ..., in Tijdschrift voor Industriële Cultuur, 13, (1995), nr. 1, p. 40-48.

Een belangrijk deel van het privé- en beroepsleven van Eduard Anseele (1856-1938) speelde zich af in de Minnemeerswijk. Anseele woonde van 1880 tot 1923 in de Ham en van 1923 tot 1938 in de Baudelostraat. Geîllustreerd. 


\section{CHARLES, R. DE HERDT, M.C. LALEMAN}

495. DORIKENS M.F., Leo Baekeland. Van Gentse Straatjongen tot multimiljonair, in Tijdschrift voor Industriële Cultuur, 13, (1995), nr. 2, p. 1936.

496. MEGANCK L., André Claessens (1904-1960): een onbekend Gents modernist, in Interbellum, 15, (1995), nr. 2, p. 6-14.

Beknopte studie van het werk van de architect, op basis van zijn persoonlijk archief. Geilllustreerd.

497. JONGMANSF., Recrutement au 19e siècle, de mathématiciensétrangers par l'Université de Liège, in Actes du LIe Congrès de la Fédération des Cercles d'Archéologie et d'Histoire de Belgique, Liège, 1994, nr. 2, p. 600-611.

Met een korte biografische schets van de wiskundige Germinal Dandelin (1794-1847), zoon van de prefect van het Scheldedepartement en vriend van Quetelet, die zijn jeugd en eerste studietijd in Gent doorbracht.

498. DE BUCK R., Zeger de Kortrijkzaan (Sohier le Courtroisin), in Ghendtsche Tydinghen, 24, (1995), nr. 2, p. 66-71.

499. STUYVER P., Pastoor Petrus De Meerleer ${ }^{\circ} 1830-\uparrow 1912$, in Mededelingen van de Heemkundige Kring van Erpe-Mere, 35, (1995), nr. 3, p. 44-57.

500. DEVOLDER L., Een Drongense Hero in Engeland tijdens WO I, in Dronghine. Jaarboek, (1995), p. 75-77.

Over het wedervaren van soldaat Emiel Devolder in Tummerings (Engeland).

501. DEWAELE O., De schapen zien de wolniet. Een communist in de val van de Gestapo, Antwerpen, 1995,156 blz.

Levensverhaal van Oscar De Waele (Gent, 1926) die zich als communist engageerde in het ondergrondse verzet tegen Hitler, tot hij in 1943 door de Gestapo werd gearresteerd.

502. POELMAN R., Bloemist Auguste Haerens, in Heemkundig Nieuws, 23, (1995), nr. 1, p. 5-6.

503. GESQUIERE I., Alice Heyman-Béviaire (1883-1954). Een geëngageerde socialiste, in GUBIN E. en L. VAN MOLLE (red.), Vergeten pioniers. Tien vrouwen in de politiek. De gemeenteraadsverkiezingen van 1921, Brussel, 1994, p. 35-43.

Beschrijving van het engagement van Alice Heyman-Béviaire binnen de Gentse Socialistische Propagandaclub voor Werkvrouwen. 
504. VAN DER LINDEN R., In memoriam Lode Hoste, in Oostvlaamse Zanten, LXIX, (1994), nr. 4, p. 198-200.

Lode Hoste (Guildford 1918-Gent 1994) profileerde zich als gedreven volkskundige maar vooral door zijn medewerking aan het AMSAB. In 1964 werd hij conservator van het Museum voor Volkskunde en in 1974 hield hij het BSP-Archief Gent-Eeklo, de voorganger van het AMSAB open. Zie ook AMSAB-Tijdingen, n.r., (1995), nr. 26, p. 3.

505. Emiel Moyson (Gent ${ }^{\circ} 9 / 1 / 1838$-Haut Pré 1/12/1868) Een kronologie van zijn leven en werk, in G.O.V. Heraut, 29, (1994), nr. 6, p. 29-38.

506. VAN HAUWAERT K., Hommage aan Emiel Poetou, in Ghendtsche Tydinghen, 24, (1995), nr. 4, p. 211-216.

Levensschets van de beeldend kunstenaar Emiel Poetou (Gent, 18851975), met een inventaris van zijn werken en overzicht van tentoonstellingen waaraan hij deelnam.

507. DEVLEESHOUWER R., Henri Rolin 1891-1973. Une voie singulière, une voix solitaire, (Institut de Sociologie. Sociologie politique), Bruxelles, 1994, $611 \mathrm{blz}$.

Geïllustreerde biografie van de prominente jurist, politicus en professor van katholieke Gentse afkomst die in 1925 kabinetschef van de regering Vandevelde werd en in 1931 toetrad tot de Belgische Werkliedenpartij; hij was senator van 1932 tot 1968.

508. MAES D., Gent elders ontmoet. Het monument van Petrus Jozef Triest te Brussel, in Ghendtsche Tydinghen, 24, (1995), nr. 4, p. 222-224.

Kanunnik Triest, geboren te Brussel in 1760 , verrichtte sociaal en liefdadigheidswerk te Gent en kreeg na zijn dood in 1836 een praalgraf in de Sint-Michielskathedraal te Brussel.

509. WILS L., Vijftig jaar geleden overleed Kamiel Van Caeneghem: de grondlegger van een flamingantische volksbeweging, in Wetenschappelijke tijdingen, LIII, (1994), nr. 4, p. 249-253.

510. VAN DER LINDEN R., In memoriam René Van de Zijpe 1926-1994, in Oostvlaamse Zanten, LXIX, (1994), nr. 3, p. 126.

Eminent Grimm-kenner ( ${ }^{\circ}$ Velzeke- $\nmid$ Zottegem $)$, startte na studies aan de RUG met de opbouw van een gespecialiseerde Grimm-bibliotheek die hij later schonk aan het Brüder Grimm-Museum te Kassel (D).

511. DE GROOTE S., Op het Campo Santo, in Heemkundig Nieuws, 22, (1994), nr. 3, p. 2-5.

Nota over het leven en het werk van beeldhouwer Antoon van Eenaeme (1827-1872). Grafmonumenten van diens hand, onder andere ter ere van 


\section{CHARLES, R. DE HERDT, M.C. LALEMAN}

Prudens Van Duyse, sieren een deel van de begraafplaats Campo Santo te Sint-Amandsberg. Geîllustreerd.

512. BAUTERS L., M.C.LALEMAN, A. LENS, D. LIEVOIS en G. STOOPS, De grafsteen van Antoon Van Hille in de kerk van de geschoeide karmelieten te Gent, in Stadsarcheologie. Bodem en monument in Gent, 18, (1994), nr. 2, p. 5-28.

De opgravingscampagne 1994 in de voormalige Karmelietenkerk aan de Lange Steenstraat bracht twee imposante grafstenen aan het licht. De studie van de inscriptieresten op één ervan leidde naar Antoon Van Hille die op 13 mei 1570 overleed. De bijeengesprokkelde gegevens lieten toe een vrij uitgebreide levensschets te reconstrueren van deze raadsheercommissaris in dienst van de Spaanse koning. Behalve zijn band met het klooster van de geschoeide karmelieten is de verwevenheid van dit personage met de politieke gebeurtenissen en godsdiensttroebelen evident. In de bijdrage wordt ook ruimschoots ingegaan op een triptiek waarop zijn wapenschild en dat van zijn echtgenote Martine van Zevecote voorkomen en dat in het Museum voor Schone Kunsten in Gent wordt bewaard. Geillustreerd.

513. VANGANSBEKE J., Dokter Leon Van Hooreweghe (1900-1960) in Dronghine. Jaarboek, (1995), p. 79-90.

Levensbeschrijving van een sociaal voelend dorpsdokter. Geillustreerd.

514. EVRARD J., Retrospectieve tentoonstelling Antoon en Luc Van Parys, (Het Toreken), Gent, 1995, $40 \mathrm{blz}$.

Overzicht van het beeldhouwwerk van vader Antoon ( Deinze 18841968) en zoon Luc Van Parys (Deinze 1920-Gent 1991). Geillustreerd. Zie ook diverse opstellen in het Jaarboek Kunst- en Oudheidkundige Kring van Deinze, 62, (1995): CASSIMAN P., Antoon Van Parys biografisch (p. 5-23), ID., Antoon Van Parys, Luc Van Parys, een thematische en stilistische benadering (p. 57-234), EVRARD J., Een leven met vader en zoon Van Parys (p. 25-56) en VAN DOORNE V. en G. VAN BEVERSLUYS, Werk van Antoon Van Parys op de kerkhoven van Groot-Deinze (p. 235-241).

515. KLUYSKENS P., Pieter-Norbert Van Reysschoot, in Ghendtsche Tydinghen, 24, (1995), nr. 1, p. 2-12.

Beschrijving van leven en werk van de schilder van het bas-reliëf (Gent 1738-1795).

516. VANELSLANDE R., Marcus van Vaernewijk, de beeldhouwer (vader van Marcus van Vaernewijck, kronijkschrijver), in Ghendtsche Tydinghen, 24, (1995), nr. 1, p. 23-31. 
517. DE MAEYER J., De rode baron. Arthur Verhaegen 1847-1917, (KADOC-Studies, 18), Leuven, 1994 , 696 blz.

Geilllustreerde biografie van de Brusselse ultramontaan en volksvertegenwoordiger, tevens architect-glazenier in de neogotische traditie; één van de sociaal geëngageerde protagonisten van de Gentse Antisocialistische Werkliedenbond, van de Oostvlaamse Landbouwersbond en stichter van de krant Het Volk. Met uitgebreid biografisch repertorium, index van corporaties, tijdschriften en plaatsnamen.

518. Liber Amicorum Adriaan Verhulst, (Willemsfonds), Gent, 1995.

Hulde uitgave voor historicus Prof. Dr. Adriaan Verhulst $\left({ }^{\circ} 1929\right)$, waarin zijn verdiensten voor de Vlaamse Beweging, voor de ontplooiing van het pluralistisch cultuurleven in Vlaanderen, voor liberalisme en vrijzinnigheid en voor de openbare omroep, maar vooral zijn verdiensten als voorzitter van het Willemsfonds worden toegelicht. Het boek omvat daarover bijdragen van L. PONTEUR, W. PREVENIER, P. VAN BRABANT, C. DERIDDER, M. OUKHOW, G. DECLERCQ,P. VANDENBUSSCHE, F. GROOTJANS, H. VAN VELTHOVEN, L. APOSTEL, R. STRYBOL en E. WITTE. In een derde deel wordt A. VERHULST zelf aan het woord gelaten en worden een aantal basisteksten van zijn hand gepubliceerd, die zijn essentiële bijdrage tot de vermelde ontwikkelingsaspecten in een recent verleden mede onderstrepen.

519. DECLERCK K. (red.), J.E. Verschaffelt (1870-1955), (Uit het verleden van de RUG, nr. 37), Gent, 1995, $113 \mathrm{blz}$.

Bijdragen van $B$. VAN CAMP over de loopbaan van deze natuurkundige en zijn engagement in de Vlaamse Beweging (p. 5-75) en van $M$. DORIKENS en L. DORIKENS-VANPRAET over zijn wetenschappelijk werk (p. 77-113). Geilllustreerd, met bibliografie en kritisch apparaat.

520. PODEVIJN D., Charles Vuylsteke sr. en jr. Fine-fleurvan de Belgische sierteelt, in Tijdschrift voor Industriële Cultuur, 13, (1995), nr. 2, p. 1317. 


\section{CHARLES, R. DE HERDT, M.C. LALEMAN}

Index op auteursnamen

\begin{tabular}{|c|c|c|c|}
\hline ADRIAENSSENS & 366 & DE CLERCK K. & 519 \\
\hline AERTS E. & 251 & DECLERCQ G. & 518 \\
\hline APOSTEL L. & 518 & DE CLERCQ R. & 454 \\
\hline ART J. & 292 & DE COCK A.M. & 328 \\
\hline AUDOOREN F. & 443 & DE COCKER J. & 257 \\
\hline BAELDE M. & 251 & DE COSTER P. & 300 \\
\hline BAILLIEUL B. & 293,444 & DECREUS F. & 413 \\
\hline BALTHAZAR H. & 324 & DE DECKER P. & 331 \\
\hline BAUTERS L. & $367,368,369,512$ & DE GEEST D. & 413 \\
\hline BEKAERT G. & 370 & DEGRAEUWE G. & 456 \\
\hline BERGMANS A. & 282 & DE GROOTE S. & 511 \\
\hline BERINGS G. & 354 & DEGRYSE K. & 292 \\
\hline BLUEBAUM D. & 411 & DE HERDT $R$. & 258,349 \\
\hline BOERJAN G. & 445 & DE KLERK A. & 369 \\
\hline BOERSMA O. & 318 & DE KOOKER H.W. & 259 \\
\hline BOGAERT D. & 347 & DE LILLE G. & 260 \\
\hline BOHEZ R. & 372 & DE MAAR F. & 457 \\
\hline BONTINCK J. & 446 & DE MAEYER J. & 517 \\
\hline BOONE M. & 292,303 & DE MEULEMEESTER J. & 283 \\
\hline BOUCKAERT B. & 270 & DE MEUTER I. & 485 \\
\hline BOURGOIS M. & 252 & DEMEY A. & 395 \\
\hline BRINKMAN P. & 412 & DEMIDDELE $\mathrm{H}$. & 284,440 \\
\hline BROGET G. & 447 & DE NAVE $F$. & 317 \\
\hline BRYSSE A. & 448 & DENECKERE G. & $328,332,333$ \\
\hline BUTAYE $\mathrm{H}$. & 365 & DENEWET L. & 458 \\
\hline BUYLE M. & 282 & DEN HARTOG E. & 414 \\
\hline CAMBIER G. & 493 & DE PATOUL B. & 415 \\
\hline CAPITEYN A. & 328 & DE PAU F. & 370 \\
\hline CASSIMAN P. & 355,514 & DEPAUW C. & 317 \\
\hline CHARLES L. & $253,254,255,256,373$ & DE PERMENTIER C. & 377 \\
\hline CLAEYS U. & 369 & DEPREZ A. & 416 \\
\hline CLAUS H. & 413 & DE RIDDER C. & 518 \\
\hline COIGNEAU D. & 297 & DEROM S. & 378,379 \\
\hline COLLEN-JANSSE & NS J. & DE SCHEPPER H. & 251 \\
\hline COLLUMBIEN $\mathrm{H}$. & 348 & DESEYN G. & $28,350,351,494$ \\
\hline COOSMANS T. & 432 & DESMET J. & 459 \\
\hline COPPEJANS-DES & MEDT $\mathrm{H}$. & DE SMET M.J. & 450 \\
\hline COPPENS H. & 251 & DE SUTTER C. & 372,380 \\
\hline COUCKE M.-T. & 313 & DE TREMERIE M. & 460 \\
\hline CROMBE P. & 299 & DETREMMERIE C. & 459 \\
\hline DAEM M. & 449,450 & DEVAUX J. & 305 \\
\hline DAEMEN J. & 361 & DEVLEESHOUWER R. & 507 \\
\hline DAMBRUYNE J. & 314,375 & DEVOLDER K. & 261 \\
\hline DE BACKER C. & 438,439 & DE VOLDER L. & 500 \\
\hline DE BAETS A. & 451 & DE VOS J. & 417 \\
\hline DE BAETS H. & 330 & DEVOS P. & 324 \\
\hline DE BELIE A. & 313 & DE VREE F. & 413 \\
\hline DEBRUYNE R.K. & 373 & DE VRIENDT J. & 461 \\
\hline DE BUCK R. & $294,304,452,453,498$ & DE VRIENDT-MORES R. & 462 \\
\hline DE CAUTER L. & 369 & DEVRIESE L. & 381,382 \\
\hline \multirow[t]{2}{*}{ DECAVELE J. } & $295,304,315,373,376$, & DE WAELE O. & 501 \\
\hline & 400,413 & DE WEERDT D. & 328 \\
\hline DECEULAER $\mathrm{H}$. & 316 & D'HOKER M. & 334 \\
\hline
\end{tabular}




\section{BIBLIOGRAFIE VAN DE GESCHIEDENIS VAN GENT 1994-1995}

\begin{tabular}{|c|c|c|c|}
\hline D'HOLLANDER J. & 418 & LIS C. & $314,321,322$ \\
\hline D'HONDT B. & 262 & LOECKX A. & 370 \\
\hline DHONDT L. & 335 & LOUIS E. & 356 \\
\hline DORIKENS-VAN PR & ET L. & MAES D. & $357,468,508$ \\
\hline DORIKENS M.F. & 495,519 & MARINUS M.J. & 292 \\
\hline DUBOIS M. & $324,370,383,384$ & MATTELAER J.J. & 470 \\
\hline EECKHOUT P. & 415 & MATTHYS A. & 283 \\
\hline ERAUW H. & 387 & MEGANCK L. & $394,395,496$ \\
\hline ERVYNCK A. & 284,440 & MENGE S. & 353 \\
\hline EVERAERT G. & 373 & MERTENS J. & 267 \\
\hline EVRARD A. & 462 & MERTENS S. & 419 \\
\hline EVRARD J. & 514 & MEUL V. & 396 \\
\hline FABRI R. & 324 & MURRAY A.V. & 307 \\
\hline FLOUR E. & 263 & MUSSCHOOT A.M. & $297,328,433$ \\
\hline FRANCOIS L. & 328,432 & NEIRYNCK F. & 471 \\
\hline GESQUIERE I. & 503 & NICHOLAS D. & 308 \\
\hline GINSBURGH V. & 419 & NOLLET P. & 446 \\
\hline GISTELINCK F. & 319 & NYS L. & 427 \\
\hline GOEMINNE L. & 458 & NYS R. & 397 \\
\hline GORIS M. & 306 & OLLIVIER $\mathrm{H}$. & 398 \\
\hline GROOTJANS F. & 518 & ORIS M. & 269 \\
\hline GUBIN E. & 503 & OSSIEUR E. & 472 \\
\hline HAMELEERS M. & 274 & OUKHOW M. & 518 \\
\hline NANAWALT B. & 308 & PAERL H. & 471 \\
\hline HAUDENHUYSE G. & 463,464 & PALINCKX K. & 338 \\
\hline HEMMERIJCKX R. & 336 & PAULISSEN G. & 370 \\
\hline HEMMINK G.J. & 413 & PAULY M. & 269 \\
\hline HENDRIKS J. & 369 & PAUWELS W. & 339 \\
\hline HEYMANS F. & 413 & PILLE F. & 296 \\
\hline HEYRMAN P. & 337 & PITTOMVILS K. & 340,353 \\
\hline HOFFSUMMER P. & $285,367,385$ & PLEIJ H. & 297 \\
\hline HOOZEE R. & 429 & POELMAN R. & $268,473,474,502$ \\
\hline HOUBRECHTS D. & $285,367,385$ & PODEVIJN D. & 520 \\
\hline HUMMELEN W. & 297 & PONTEUR L. & 518 \\
\hline HUYS P. & 420 & PORIAU M. & 485 \\
\hline JACQUES C. & 263 & POULAIN N. & $328,395,399$ \\
\hline JANSSENS G. & 265 & PREVENIER W. & 518 \\
\hline JAUMAIN S. & 337 & RAVESCHOT P. & 386 \\
\hline JELSMA A.J. & 318 & RENSON R. & 334 \\
\hline JONGMANS F. & 497 & REYERSON K. & 308 \\
\hline KERCKHAERT N. & 389 & RIDER J. & 309 \\
\hline KLUYSKENS P. & $304,390,515$ & ROGGE M. & 302 \\
\hline LAGROU E. & 370 & RYCKAERT M. & 269,324 \\
\hline \multirow{2}{*}{ LALEMAN M.C. 25} & $283,286,287,288$ & SABBE M. & 319 \\
\hline & $368,373,386,512$ & SACHTLEBEN V. & 352 \\
\hline LAMARCQ D. & $425,441,465$ & SCHEEPSMA W.F. & 358 \\
\hline LANCLUS $\mathrm{K}$. & 391 & \multicolumn{2}{|c|}{ SCHENKEVELD-VAN DER DUSSEN } \\
\hline LANGENDRIES E. & 328 & M.A. & 297 \\
\hline LAPORTE D. & 392 & SCHEPENS E. & 475 \\
\hline LEKENS L. & 304 & SCHMIDT P. & 428 \\
\hline LENDERS P. & 321 & SCHOLLIERS P. & 341 \\
\hline LENS A. & $288,368,512$ & SCHREURS E. & 270 \\
\hline LEVIS E. & 466,467 & SELIS E. & 476 \\
\hline LIEVIJNS L. & 266 & SERRAS H. & 389 \\
\hline LIEVOIS D. $\quad 256,288$ & $\begin{array}{r}310,368,373,393, \\
512\end{array}$ & SERRUS B. & 353 \\
\hline & 512 & SMALL G. & 310 \\
\hline
\end{tabular}


L. CHARLES, R. DE HERDT, M.C. LALEMAN

SMETS M.

SMEYERS J.

SMEYERS M.

SOLY H.

SONNEVILLE A.

SPATZ H.

STEEGHERS W.

STEVENS $M$.

STOCKMAN L.

STOOPS G.

STRAUVEN F.

STROO C.

STRYBOL R.

STUYVER $P$.

SWART K.W.

TAVERNE E.

TERRYN C.

THIJS A.K.L.

TIMMERMAN F.

TISSEGHEM R.

TOLLENEER J.

T'SJOEN Y.

UYTTENHOVE P.

VAN BELLE J.L

VAN BRABANT P.

VAN BRUWAENE C.

VAN BEVERSLUYS G.

VAN BUTSELE P.

VAN CAMP B.

VAN CLEVEN J.

VAN DAMME L.

VAN DEN ABEELE R.

VANDEN BILCKE $R$.

VAN DEN BOSSCHE $H$.

VAN DEN BRINK P.

VANDEN BROECKE $S$.

VANDENBROEKE C.

VANDENBUSSCHE P.

VAN DE PERRE D.

VAN DE PERRE N.

VAN DER HAEGEN G.

VAN DER HERTEN B.

VAN DER KROGT P.

VAN DER LINDEN R.

VANDER MAELEN $H$.

VANDEVOORDE $H$.

VAN DE WALLE A.

VAN DE WALLE $R$.

VAN DE WIELE J.

VAN DOORNE G.

VAN DOORNE V.

VAN DRIESSCHE I.

VAN ELSLANDE R.

VAN ELSLANDER A.
370
297
41

$251,314,321,322$

477

401

$271,478,479,480$

429

$359,360,481$

$288,368,512$

370

415

518

499

323

324

317

251

482

361

334

430

370

272

518

304

514

273

519

432

302

442

373

402

274

362

292,325

518

483

363

299

342

274,298

$484,504,510$

275

430

311

485

365

$372,380,403$

514

369

516

433
VAN GANSBEKE J.

VAN GEERT G.

VAN GELDEREN M.

486,513

467

326

369

413

343

506

276

251

369

277

342

503

404

258

434

487

VAN PETEGHEM S.

VAN POUCKE D.

VANSCHOENBEEK G. $\quad 344,345$

VAN SELM B.

VAN SCHOOR J.

VAN SCHOUTE R.

VANTHEMSCHE G.

VAN TWEMBEKE J.

VAN TYGHEM F.

VAN VELTHOVEN $H$.

259

413

415

337

488

432

518

VAN WERVEKE A.

VANWILDEMEERSCH U. $\quad 376$

VELLE $\mathrm{K}$.

VERBEKE A.

489,490

VERHEEKE G.

VERHULST A. $\quad 518$

VERKERKEN D. 275, 278, 279

VERKERKEN W. 436

VERMEIRE M. 406

VERMEIR R. 292

VERMEULEN F. $\quad 301,302$

VEROUGSTRAETE J. 280

VERSTEGEN V. 313

VERVAET A. $\quad 407$

VERVAET B. $\quad 408$

VIANE R. $\quad 437$

VIAENE P. $\quad 281$

VISSER I. $\quad 324$

VLEESCHOUWERS C. 363

VLEESCHOUWERS M. 292

WATERSCHOOT W. 297

WILS L. $\quad 346,509$

WISSINK W.

WITDOUCK R.

306

364

518

WORTMANN A. 410

ZABEAU-VAN DER VERREN L. 400

ZOETE A. 